\title{
Pro-inflammatory gene expression and neurotoxic effects of activated microglia are attenuated by absence of CCAAT/enhancer binding protein $\beta$
}

Marco Straccia ${ }^{1,2}$, Núria Gresa-Arribas ${ }^{1,2}$, Guido Dentesano², Aroa Ejarque-Ortiz², Josep M Tusell2 , Joan Serratosa², Carme Solà ${ }^{2}$ and Josep Saura ${ }^{1 *}$

\begin{abstract}
Background: Microglia and astrocytes respond to homeostatic disturbances with profound changes of gene expression. This response, known as glial activation or neuroinflammation, can be detrimental to the surrounding tissue. The transcription factor CCAAT/enhancer binding protein $\beta$ (C/EBP $\beta)$ is an important regulator of gene expression in inflammation but little is known about its involvement in glial activation. To explore the functional role of C/EBP $\beta$ in glial activation we have analyzed pro-inflammatory gene expression and neurotoxicity in murine wild type and C/EBPß-null glial cultures.
\end{abstract}

Methods: Due to fertility and mortality problems associated with the C/EBP $\beta$-null genotype we developed a protocol to prepare mixed glial cultures from cerebral cortex of a single mouse embryo with high yield. Wild-type and C/EBP $\beta$-null glial cultures were compared in terms of total cell density by Hoechst-33258 staining; microglial content by CD11b immunocytochemistry; astroglial content by GFAP western blot; gene expression by quantitative real-time PCR, western blot, immunocytochemistry and Griess reaction; and microglial neurotoxicity by estimating MAP2 content in neuronal/microglial cocultures. C/EBP $\beta$ DNA binding activity was evaluated by electrophoretic mobility shift assay and quantitative chromatin immunoprecipitation.

Results: C/EBP $\beta$ mRNA and protein levels, as well as DNA binding, were increased in glial cultures by treatment with lipopolysaccharide (LPS) or LPS + interferon $\gamma$ (IFN $\gamma$ ). Quantitative chromatin immunoprecipitation showed binding of C/EBP $\beta$ to pro-inflammatory gene promoters in glial activation in a stimulus- and gene-dependent manner. In agreement with these results, LPS and LPS+IFNy induced different transcriptional patterns between proinflammatory cytokines and NO synthase-2 genes. Furthermore, the expressions of IL-1 $\beta$ and NO synthase-2, and consequent NO production, were reduced in the absence of C/EBP $\beta$. In addition, neurotoxicity elicited by LPS + IFN $\gamma$-treated microglia co-cultured with neurons was completely abolished by the absence of C/EBP $\beta$ in microglia.

Conclusions: These findings show involvement of C/EBP $\beta$ in the regulation of pro-inflammatory gene expression in glial activation, and demonstrate for the first time a key role for $C / E B P \beta$ in the induction of neurotoxic effects by activated microglia.

\section{Background}

Glial activation is an inflammatory process that occurs in astrocytes and microglia to re-establish homeostasis of the CNS after a disequilibrium of normal physiology. Microglia are tissue-associated macrophages that keep the CNS

\footnotetext{
* Correspondence: josepsaura@ub.edu

'Biochemistry and Molecular Biology Unit, School of Medicine, University of Barcelona, IDIBAPS, Barcelona, Spain Full list of author information is available at the end of the article
}

under dynamic surveillance. Most insults to the CNS switch microglia into an M1-like phenotype, characterized by production of pro-inflammatory cytokines, reactive oxygen/nitrogen species and prostanoids. Scavenger receptors and chemokines are also upregulated and phagocytic activity increases. An M2-like phenotype usually follows, characterized by production of interleukin-4 (IL-4), IL-10, transforming growth factor- $\beta$ and neurotrophic factor [1]. Glial activation requires massive and fine-tuned re-
C Biomed Central 
arrangements in gene transcription. The transcription factors behind this process include nuclear factor-kB, which seems to mediate early-immediate cytokine and chemokine gene responses in glial activation [2,3], and other transcription factors with a pro-inflammatory profile such as AP-1 [4], STATs [5], HIF-1 [5-7], Egr-1 [8], IRF1 [9]. On the other hand, transcription factors such as PPARs [10] or Nrf2 [11,12] play an anti-inflammatory role in glial activation.

CCAAT/enhancer binding protein $\beta(\mathrm{C} / \mathrm{EBP} \beta)$ is a candidate to regulate pro-inflammatory gene expression in glial activation. $C / E B P \beta$ is one of seven members of the $C /$ EBP subfamily of bZIP transcription factors. At least three $\mathrm{N}$-terminally truncated isoforms are known: 38-kDa Full, 35-kDa LAP and 21-kDa LIP $[13,14]$. C/EBP $\beta$ transcriptional functions in cell energy metabolism, cell proliferation and differentiation are well-characterized [15,16]. C/ EBP $\beta$ also plays a role in inflammation [17]. Promoters of many pro-inflammatory genes contain putative $\mathrm{C} / \mathrm{EBP} \beta$ consensus sequences [18-20] and C/EBP $\beta$ levels are upregulated in response to pro-inflammatory stimuli in macrophages [21] and glial cells [22-25]. Interestingly, C/EBP $\beta$ deficiency provides neuroprotection following ischemic [26] or excitotoxic injuries [27].

Several lines of evidence suggest that glial activation is involved in the pathogenesis of many neurological disorders. The present study stems from this hypothesis and from the hypothesis that there is a regulatory role for $\mathrm{C} / \mathrm{EBP} \beta$ in pro-inflammatory gene expression in neuroinflammation. To define the transcriptional role of $\mathrm{C} /$ $\mathrm{EBP} \beta$ in glial activation we have here studied proinflammatory gene profiles and neurotoxicity in glial cultures from $\mathrm{C} / \mathrm{EBP} \beta$-null mice. Our results show for the first time that absence of $\mathrm{C} / \mathrm{EBP} \beta$ attenuates proinflammatory gene expression and abrogates neuronal loss induced by activated microglia.

\section{Methods}

\section{Animals}

A colony of $\mathrm{C} / \mathrm{EBP}^{+/-}$[28] mice on a C57BL/6-129S6/ SvEv background was maintained. Animals from this colony showed no serological evidence of pathological infection. The animals were group-housed (5-6) in solid floor cages and received a commercial pelleted diet and water ad libitum. Experiments were carried out in accordance with the Guidelines of the European Union Council (86/609/EU) and following the Spanish regulations (BOE 67/8509-12, 1988) for the use of laboratory animals, and were approved by the Ethics and Scientific Committees from the Hospital Clínic de Barcelona.

\section{DNA extraction and genotyping}

Genomic DNA was isolated from $2 \mathrm{mg}$ liver samples using Extract-N-AmpTissue PCR Kit (Sigma-Aldrich,
XNAT2) following kit instructions. PCR amplification was performed in $20 \mu \mathrm{l}$ total volume, using $1 \mu \mathrm{l}$ of tissue extract, $0.8 \quad \mu \mathrm{M} \quad \mathrm{C} / \mathrm{EBP} \beta-1 \mathrm{~s}$ forward primer (AAgACggTggACAAgCTgAg), $0.4 \mu \mathrm{M}$ C/EBP $\beta$-NeoAs (CATCAgAgCAgCCgATTgTC) and $0.4 \mu \mathrm{M} \mathrm{C/EBP} \beta$ 4As (ggCAgCTgCTTgAACAAg TTC) reverse primers. Samples were run for 35 cycles $\left(94^{\circ} \mathrm{C}\right.$ for $30 \mathrm{~s}, 59^{\circ} \mathrm{C}$ for $30 \mathrm{~s}, 72^{\circ} \mathrm{C}$ for $90 \mathrm{~s}$ ).

\section{Cortical mixed glial culture from a single embryo}

$\mathrm{C} / \mathrm{EBP} \beta+/$ - mice were crossed and pregnant females were sacrificed on the 19th day of gestation by cervical dislocation. Embryos (E19) were surgically extracted from the peritoneal cavity. Their livers were dissected and used to genotype the animal, whereas their brains were dissected and processed as previously described [29] with minor modifications. Cultures reached confluence after $16 \pm 3$ days in vitro (DIV) and were then subcultured.

\section{Mouse mixed glial subculture}

Each flask was washed in serum-free medium and was digested with $0.25 \%$ trypsin-EDTA solution for $5 \mathrm{~min}$ at $37^{\circ} \mathrm{C}$. Trypsinization was stopped by adding an equal volume of culture medium with FBS $10 \%$. Cells were pelleted (7 $\mathrm{min}, 180 \mathrm{~g}$ ), resuspended in $1 \mathrm{~mL}$ culture medium, and brought to a single cell suspension by repeated pipetting. Cells were seeded at 166000 cells/ $\mathrm{mL}$. These were therefore secondary cultures and they were used at $12 \pm 3$ DIV. Astrocytes were the most abundant cell type and microglial cells were approximately $20 \%$.

\section{Microglial culture}

Microglial cultures were prepared by mild trypsinization from mouse mixed glial culture as previously described [30].

\section{Primary cortical neuronal culture}

Cortical neuronal cultures were prepared from C57BL/6 mice at embryonic day 16 as described [31]. Neuronal cultures were used at 5 DIV.

\section{Primary neuronal-microglial co-cultures}

Microglial cultures were obtained as described [31]. After astrocyte removal, microglial cells were incubated with $0.25 \%$ trypsin for $10 \mathrm{~min}$ at $37^{\circ} \mathrm{C}$. Trypsinization was stopped by adding the same volume of culture medium with $10 \%$ FBS. Cells were gently scraped and centrifuged for $5 \mathrm{~min}$ at $200 \mathrm{~g}$. Pellets were resuspended in neuronal culture medium and aliquots of the cell suspension $(10 \mu \mathrm{L} /$ well $)$ were seeded on top of 5 DIV primary neuronal cultures at a final density of $4 \times 10^{5}$ cells $/ \mathrm{mL}\left(1.3 \times 10^{5}\right.$ cells $\left./ \mathrm{cm}^{2}\right)$. 


\section{In vitro treatments}

Mixed glial cultures: The culture medium was replaced $24 \mathrm{~h}$ prior to treatment. Mixed glial cultures were treated with $100 \mathrm{ng} / \mathrm{mL}$ lipopolysaccharide (LPS, SigmaAldrich, L-2654, E. coli serotype 026:B6) and $0.1 \mathrm{ng} / \mathrm{mL}$ recombinant mouse interferon- $\gamma$ (IFN $\gamma$, Sigma-Aldrich, I4777) prepared from $x 10$ solutions.

Neuronal-primary microglia co-cultures: $100 \mathrm{ng} / \mathrm{mL}$ LPS and $30 \mathrm{ng} / \mathrm{mL}$ IFN $\gamma$ were added to the culture medium one day after seeding primary microglial cells on top of neuronal cultures.

\section{Nitrite assay}

NO production was assessed by the Griess reaction. Briefly, $50 \mu \mathrm{L}$ aliquots of culture supernatants were collected $48 \mathrm{~h}$ after LPS+IFN $\gamma$ treatment, and incubated with equal volumes of Griess reagent (1\% sulphanilamide, $0.1 \% \mathrm{~N}$-(1-naphthyl)ethylendiamine dihydrochloride, and $5 \%$ phosphoric acid) for $10 \mathrm{~min}$ at room temperature (RT). Optical density at $540 \mathrm{~nm}$ was determined using a microplate reader (Multiskan spectrum, Thermo Electron Corporation). Nitrite concentration was determined from a sodium nitrite standard curve.

\section{Electrophoretic mobility shift assay}

Nuclear extracts were prepared as described [32] with a few modifications. Nuclear protein was extracted from mixed glial cultures after $2 \mathrm{~h}$ LPS or LPS + IFN $\gamma$ treatment. Cells from two wells of 6-well plate were scrapped into cold $0.01 \mathrm{M}$ phosphate-buffered saline (PBS, $\mathrm{pH}$ 7.4 ) and centrifuged for $4 \mathrm{~min}, 4500 \mathrm{~g}$ at $+4{ }^{\circ} \mathrm{C}$. The resulting pellet was resuspended in $400 \mu \mathrm{L}$ of buffer A: $10 \mathrm{mM}$ HEPES pH 7.9, $10 \mathrm{mM} \mathrm{KCl,} 0.1 \mathrm{mM}$ EDTA, 0.1 mM EGTA, $0.5 \mathrm{mM}$ phenylmethylsulphonyl fluoride (PMSF) and $1 \mathrm{mM}$ dithiothreitol (DTT) and cells were swollen on ice for $15 \mathrm{~min}$. After addition of $25 \mu \mathrm{L}$ of 10\% Igepal CA-630 (Sigma-Aldrich, I8896), cells were vigorously vortexed for $10 \mathrm{~s}$ and incubated for $10 \mathrm{~min}$ on ice, then a 10-min centrifugation at $13200 \mathrm{~g}$ was performed and the pellets were resuspended in $50 \mu \mathrm{L}$ of buffer $\mathrm{C}$ consisting of $20 \mathrm{mM}$ HEPES pH 7.9, 0.4 M $\mathrm{NaCl}, 1 \mathrm{mM}$ EDTA, $1 \mathrm{mM}$ EGTA, $1 \mathrm{mM}$ PMSF and 1 mM DTT. Solutions A, B, C and PBS were supplemented with protease inhibitor cocktail Complete ${ }^{\circledR}$ (Roche, $1836145)$. After $2 \mathrm{~h}$ of shaking at $4^{\circ} \mathrm{C}$, nuclei were pelleted by a 5 min spin at $2000 \mathrm{~g}$. The supernatant containing nuclear proteins was collected and protein amount was determined by the Lowry assay (Total Protein kit micro-Lowry, Sigma-Aldrich, TP0300). Oligonucleotides containing C/EBP consensus sequences (Santa Cruz Biotechnology, sc-2525) were labelled at their 3'end using $\left[\alpha-{ }^{33} \mathrm{P}\right] \mathrm{dATP}(3000 \mathrm{Ci} / \mathrm{mmol}$; Dupont-NEN, NEG-612H) and terminal deoxynucleotidyltransferase (TdT; Oncogene Research Products, PF060), and purified using illustra MicroSpin G-50 Columns (GE, 27-5330-01). Five micrograms of nuclear proteins were incubated for $30 \mathrm{~min}$ at RT with the labelled oligonucleotides (25000 cpm/reaction assay) in binding buffer (20\% glycerol, $5 \mathrm{mM} \mathrm{MgCl}_{2}, 2.5 \mathrm{mM}$ EDTA, $2.5 \mathrm{mM}$ DTT, $50 \mathrm{mM}$ Tris- $\mathrm{HCl}, 250 \mathrm{mM} \mathrm{NaCl}$ and $0.2 \mathrm{mg} / \mathrm{mL}$ Poly(dI:dC)). After the addition of Hi-Density TBE buffer to samples (15\% Ficoll type 400, 1x TBE, 0.1\% Bromophenol Blue, 0.1\% Xylene Cyanol), proteins were separated by electrophoresis on a 6\% DNA retardation gel (Invitrogen, EC6365BOX) at $4^{\circ} \mathrm{C}, 90 \mathrm{~min}$ at $100 \mathrm{~V}$ in $0.5 \mathrm{x}$ TBE buffer. In supershift assay, $0.5 \mu \mathrm{g}$ of rabbit anti-mouse C/EBP $\beta$ (Santa Cruz Biotechnology, sc-150) or IgG (Santa Cruz Biotechnology, No.sc-2027) were added $10 \mathrm{~min}$ before oligonucleotide incubation.

\section{Total protein extraction}

Protein levels were determined in primary mixed glial cells $16 \mathrm{~h}$ after treatments. For isolation of total proteins, two wells from 6-well plates were used per condition. After a cold PBS wash, cells were scrapped and recovered in $100 \mu \mathrm{L}$ per well of RIPA buffer (1\% Igepal CA-630, $5 \mathrm{mg} / \mathrm{mL}$ sodium deoxycholate, $1 \mathrm{mg} / \mathrm{mL}$ sodium dodecyl phosphate (SDS) and protease inhibitor cocktail Complete $^{\circledR}$ in PBS). The content of the wells was pooled, sonicated, centrifuged for $5 \mathrm{~min}$ at $10400 \mathrm{~g}$ and stored at $-20^{\circ} \mathrm{C}$. Protein amount was determined by the Lowry assay.

\section{Western blot}

Fifty micrograms of denatured $\left(2.5 \mathrm{mM} \mathrm{DTT}, 100^{\circ} \mathrm{C}\right.$ for $5 \mathrm{~min})$ total protein extracts were subjected to $10 \%$ SDS-PAGE and transferred to a PVDF membrane (Millipore, IPVH00010) for $90 \mathrm{~min}$ at $1 \mathrm{~mA} / \mathrm{cm}^{2}$. After washing in Tris-buffered saline (TBS: $20 \mathrm{mM}$ Tris, $0.15 \mathrm{M}$ $\mathrm{NaCl}, \mathrm{pH} 7.5$ ) for $5 \mathrm{~min}$, dipping in methanol for $10 \mathrm{~s}$ and air drying, the membranes were incubated with primary antibodies overnight at $4^{\circ} \mathrm{C}$ : polyclonal rabbit antiC/EBP $\beta$ (1:500, Santa Cruz Biotechnology, sc-150), monoclonal mouse anti-NO synthase-2 (NOS2; 1:200, BD Transduction Laboratories, 610431), monoclonal mouse anti- $\beta$ actin (1:100000, Sigma-Aldrich, A1978) and polyclonal rabbit anti-GFAP (1:10000, DakoCytomation, Z0334) diluted in immunoblot buffer (TBS containing $0.05 \%$ Tween-20 and 5\% no-fat dry milk). Then, the membranes were washed twice in $0.05 \%$ Tween- 20 in TBS for $15 \mathrm{~s}$ and incubated in horseradish peroxidase (HRP)-labelled secondary antibodies for $1 \mathrm{~h}$ at RT: donkey anti-rabbit (1:5000, GE, NA934) or goat anti-mouse (1:5000, Santa Cruz Biotechnology, sc-2055). After extensive washes in $0.05 \%$ Tween-20 in TBS, they were incubated in ECL-Plus (GE, RPN2132) for $5 \mathrm{~min}$. Membranes were then exposed to the camera of a VersaDoc System (Bio-Rad), and pixel intensities of the 
immunoreactive bands were quantified using the percentage adjusted volume feature of Quantity One 5.4.1 software (Bio-Rad). Data are expressed as the ratio between the intensity of the protein of interest band and the loading control protein band ( $\beta$-actin).

\section{Quantitative real time PCR (qPCR)}

mRNA expression was determined in mouse mixed glial cells $6 \mathrm{~h}$ after treatments. For isolation of total RNA, 2 wells of 24-well plates were used per experimental condition. Total RNA was isolated using an Absolutely RNA Miniprep kit (Agilent Technologies-Stratagene 400.800) and $100 \mathrm{ng}$ of RNA for each condition was reverse-transcribed with random primers using Sensiscript RT kit (Qiagen, 205213). cDNA was diluted 1/25 and $3 \mu \mathrm{L}$ were used to perform qPCR. The primers (Roche) were used at a final concentration of $300 \mathrm{nM}$ (Table 1). $\beta$-Actin and Rn18s mRNAs levels are not altered by treatments (data not shown). qPCR was carried out with IQ SYBR Green SuperMix (Bio-Rad, 1708882 ) in $15 \mu \mathrm{L}$ of final volume using iCycler MyIQ equipment (Bio-Rad). Primer efficiency was estimated from standard curves generated by dilution of a cDNA pool. Samples were run for 40 cycles $\left(95^{\circ} \mathrm{C}\right.$ for $30 \mathrm{~s}, 60^{\circ}$ $\mathrm{C}$ for $1 \mathrm{~min}, 72^{\circ} \mathrm{C}$ for $30 \mathrm{~s}$ ). Amplification specificity was confirmed by analysis of melting curves. Relative gene expression values were calculated with the comparative Ct or $\Delta \Delta \mathrm{Ct}$ method [33] using iQ5 2.0 software (Bio-Rad). Ct values were corrected by the amplification efficiency of the respective primer pair which was estimated from standard curves generated by dilution of a cDNA pool.

\section{Quantitative chromatin immunoprecipitation (qChIP)} qChIP was performed as previously described [34] with modifications. Briefly, primary mixed glial cultures were cross-linked in $1 \%$ formaldehyde for $10 \mathrm{~min}$ at RT, quenched with $125 \mathrm{mM}$ glycine for $5 \mathrm{~min}$ a RT. Cells were washed in PBS with $1 \mathrm{mM}$ PMSF and protease inhibitor mix, then the cells were resuspended with 150 $\mathrm{mM} \mathrm{NaCl}, 50 \mathrm{mM}$ Tris-HCL pH7.5, 5 mM EDTA, 0.5\% vol/vol NP-40, 1\% vol/vol Triton X-100, 1\% wt/vol SDS,
$1 \mathrm{mM}$ PMSF, protease inhibitor mix (IP Buffer). Chromatin shearing was obtained from $2 \times 10^{5}$ cells using Labsonic $\mathrm{M}$ sonicator $(7 \times 30 \mathrm{~s}$ on and $30 \mathrm{~s}$ off; cycle $0.8 ; 100 \%$ amplitude). In parallel, an aliquot of chromatin sheared from each sample was separated as a loading control for the experiment (input). The protocol for chromatin immunoprecipitation (ChIP) was as follows: first, $10 \mu \mathrm{L}$ of Dynabeads ${ }^{\circledR}$ protein A (Invitrogen, 100.01D) were washed twice with $22 \mu \mathrm{L}$ of cold IP Buffer (without SDS). Then the beads were resuspended in $11 \mu \mathrm{L}$ of IP Buffer. Next, $90 \mu \mathrm{L}$ of IP Buffer was added to a PCR tube with $10 \mu \mathrm{L}$ of pre-washed protein Abeads. Two micrograms of polyclonal rabbit $C / E B P \beta$ antibody (Santa Cruz Biotechnology, sc-150X) or with 2 $\mu \mathrm{g}$ of rabbit IgG (Santa Cruz Biotechnology, sc-2027) as negative control were added and the mixture was incubated at $40 \mathrm{rpm}$ on a rotating wheel for at least $2 \mathrm{~h}$ at $4^{\circ} \mathrm{C}$. Then, the tube was placed on a magnetic rack for 1 min. The supernatant was discarded and $100 \mu \mathrm{L}$ of sheared chromatin was added. Samples were incubated overnight at $40 \mathrm{rpm}$ rotation at $4^{\circ} \mathrm{C}$. Finally, the tube was placed on the magnetic rack for $1 \mathrm{~min}$. The supernatant was discarded and the immunoprecipitation complex was washed three times with $100 \mu \mathrm{L}$ of IP Buffer for $4 \mathrm{~min}$ on a rotating wheel and placed in the magnetic rack again for 1 min to discard the supernatant. The fourth wash was done with $10 \mathrm{mM}$ Tris- $\mathrm{HCl} \mathrm{pH}$ 8.0 and $10 \mathrm{mM}$ EDTA buffer. Protein was degraded by a 2-h incubation at $68^{\circ} \mathrm{C}$ in $200 \mu \mathrm{L}$ of IP Buffer complemented with $50 \mu \mathrm{g} / \mathrm{mL}$ of proteinase $\mathrm{K}$. DNA was isolated with phenol-chloroform-isoamylalcohol 25:24:1 (Sigma-Aldrich, 25666 and P4556) extraction. Input and ChIP samples were analyzed with qPCR using SYBR green (Bio-Rad). Three microliters of input DNA (diluted 1/50) and ChIP were amplified in triplicate in 96-well optical plates using a MyIQ Bio-Rad Real Time Detection System. The C/EBP $\beta$ binding site in the IL-10 promoter was used as a positive control [35]. MatInspector was used to identify the proximal C/EBP $\beta$ consensus sequence in each analyzed promoter. The sequences for each amplified locus are indicated in the table 2. Samples were run for 45 cycles $\left(95^{\circ} \mathrm{C}\right.$ for $30 \mathrm{~s}$,

Table 1 Primers used in quantitative real time PCR.

\begin{tabular}{|c|c|c|c|}
\hline Target Gene & Accession & Primer forward $\left(5 \rightarrow 3^{\prime}\right)$ & Primer reverse $\left(5 \rightarrow 3^{\prime}\right)$ \\
\hline NOS2 & NM_010927.3 & ggCAgCCTgTgAgACCTTg & gCATggAAgTgAAgCgTTC \\
\hline $\operatorname{IL} 1 \beta$ & NM_008361.3 & TggTgTgTgACgTTCCCATTA & CAgCACgAggCTTाTTgTTg \\
\hline IL6 & NM_031168.1 & CCAgTTggTAgCATCCATC & CCgCAgAggAgACTTCACAg \\
\hline TNF $\alpha$ & NM_013693.2 & TgATCCgCgACgTggAA & ACCgCCTggAgTTCTggAA \\
\hline TGF $\beta 1$ & NM_011577.1 & TgCgCTTgCAgAgATTAAAA & AgCCCTgTATTCCgTCTCCT \\
\hline IL4 & NM_021283, 2 & CgAggTCACAggAgAAgggA & AAgCCCTACAgACgAgCTCACT \\
\hline Actin & NM_007393.3 & CAACgAgCggTTCCgATg & gCCACAggATTCCATACCCA \\
\hline Rn18s & NR_003286.2 & gTAACCCgTTgAACCCCATT & CCATCCAATCggTAgTAgCg \\
\hline
\end{tabular}


Table 2 C/EBP $\beta$ binding sites and primers used in quantitative ChIP assay.

\begin{tabular}{|c|c|c|c|c|}
\hline $\begin{array}{l}\text { Target } \\
\text { Gene }\end{array}$ & $\begin{array}{l}\text { C/EBP } \beta \text { binding site sequence }\left(5 \rightarrow 3^{\prime}\right) \\
\text { Consensus: ATTGCGCAAT }\end{array}$ & $\begin{array}{l}\text { Genomic localization } \\
\text { respect to ATG }\end{array}$ & Primer forward $\left(5 \rightarrow 3^{\prime}\right)$ & Primer reverse $\left(5 \rightarrow 3^{\prime}\right)$ \\
\hline NOS2 & ggagTGaaGCAATga & $-892 /-907$ & TTATgAgATgTgCCCTCTgC & CCACCTAAggggAACAgTgA \\
\hline $\operatorname{IL} 1 \beta$ & tgtgTgaaGaAAgaa & $-16 /-31$ & TCAggAACAgTTgCCATAgC & AgACCTATACAACggCTCCT \\
\hline IL6 & gTttCCAATcagccc & $-173 /-188$ & gTTgTgATTCTTTCgATgCT & ggAATTgACTATCgTTCTTg \\
\hline TNF $\alpha$ & agggTtgGaAAgtt & $-336 /-351$ & TCTCATTCAACCCTCggAAA & CACACACACCCTCCTgATTg \\
\hline IL10 & aggATTGaGaAATaa & $-463 /-448$ & TgACTTCCgAgTCAgCAAgA & AgAggCCCTCATCTgTggAT \\
\hline
\end{tabular}

$62^{\circ} \mathrm{C}$ for $1 \mathrm{~min}, 72^{\circ} \mathrm{C}$ for $30 \mathrm{~s}$ ), for further details see qPCR methods.

\section{Immunocytochemistry}

Cultured cells were fixed with $4 \%$ paraformaldehyde in PBS for $20 \mathrm{~min}$ at RT. For immunocytochemistry using fluorescence labelling, cells were permeated with chilled methanol for $7 \mathrm{~min}$, then washed with PBS. Cells were incubated overnight at $4{ }^{\circ} \mathrm{C}$ with $7 \%$ normal goat serum (Vector, S-1000) in PBS containing 1\% Thimerosal (Sigma-Aldrich, T5125) and primary antibodies: polyclonal rabbit anti-C/EBP $\beta$ (1:500, Santa Cruz Biotechnology, sc-150), monoclonal mouse antiNOS2 (1:200, BD Transduction Laboratories, 610431), polyclonal rabbit anti-GFAP (1:1000, DakoCytomation, Z0334) and monoclonal rat anti-CD11b (1:300, Serotec, MCA711G, clone 5C6). After rinsing in PBS, cells were incubated for $1 \mathrm{~h}$ at RT with secondary antibodies: goat anti-mouse Alexa 546 (1:1000, Molecular Probes, A-11018), goat anti-rabbit Alexa 546 (1:1000, Molecular Probes A-11010), Alexa 488 (1:1000, Molecular Probes, A-11070) or goat anti-rat Alexa 488 (1:500, Molecular Probes, A-11006). After secondary antibody incubation, cells were stained with Hoechst 33258 for $7 \mathrm{~min}$. For immunocytochemistry using peroxidase labelling, cells were permeated and endogenous peroxidase activity was blocked by incubation with $0.3 \% \mathrm{H}_{2} \mathrm{O}_{2}$ in methanol for $10 \mathrm{~min}$. Non-specific staining was blocked by incubating the cells with $10 \%$ normal goat serum in PBS containing 1\% BSA for $20 \mathrm{~min}$ at RT. The cells were then incubated with monoclonal mouse anti-MAP2 primary antibody (1:2000, SigmaAldrich, M1406) overnight at $4^{\circ} \mathrm{C}$. In MAP2 staining, biotinylated horse anti-mouse secondary antibody (1:200, Vector, BA-2000) for $1 \mathrm{~h}$ at RT. Following incubation with ExtrAvidin ${ }^{\circledR}$-Peroxidase (1:500, SigmaAldrich, E2886) for $1 \mathrm{~h}$ at RT, colour was developed with diaminobenzidine (Sigma-Aldrich, D5637). The antibodies were diluted in PBS containing 1\% BSA and $10 \%$ normal horse serum (Vector, S-2000). Microscopy images were obtained with an Olympus IX70 microscope and a digital camera (CC-12, Soft Imaging System $\mathrm{GmbH}$ ).
Assessment of neuronal viability (MAP2/ABTS/ELISA)

Neuronal viability was evaluated by MAP2 immunostaining using ABTS (2, 3'-azinobisethylbenzothiazoline6-sulphonic acid) and absorbance analysis [31]. Neuronal viability was expressed as a percentage of control levels.

\section{Cell counting}

Hoechst-33258- and CD11b-positive cells were semiautomatically counted from $20 x$ photomicrographs using ImageJ 1.42I NIH software. For each experiment $(\mathrm{n}=4)$, three wells per condition were used and four fields per well were counted in a blind manner. NOS2positive cells were counted manually from 20x photomicrographs. For each experiment $(\mathrm{n}=11)$, two wells per condition were used and two fields per well were counted.

\section{Statistical analysis}

Data were analyzed using GraphPad 4.02. Two-way analysis of variance (ANOVA) followed by Bonferroni posttest was used when the effect of genotype on treatment was studied and vice versa. One-way ANOVA was used followed by Dunnet's post-test when comparing versus control or Bonferroni's post-test when comparing versus different experimental conditions. Values of $\mathrm{p}<0.05$ were considered statistically significant. Error bars are presented in all graphs as standard error of the mean (SEM).

\section{Results}

Characterization of $\mathrm{C} / \mathrm{EBP} \beta^{+/+}$and $\mathrm{C} / \mathrm{EBP} \beta^{-/-}$single embryo secondary mixed glial cultures

To study the role of $\mathrm{C} / \mathrm{EBP} \beta$ in glial activation we used $\mathrm{C} / \mathrm{EBP} \beta$-null mice. Because of the infertility of $\mathrm{C} / \mathrm{EBP} \beta$ null females and a perinatal death rate of approximately $50 \%$ for C/EBP $\beta$-null neonates, we have modified the standard procedures to prepare mixed glial cultures from CNS tissue pools of several mouse neonates and designed a protocol to prepare secondary mixed glial cultures from the cerebral cortex of one single E19-E20 mouse embryo (see Methods for details). Forty-one C/ $\mathrm{EBP} \beta$-null mice and forty-one wild-type littermates were 
used during this study. To ensure that wild-type and C/ EBP $\beta$-null glial cultures were comparable, we first analyzed total cell density and abundance of their two main cell types, astrocytes and microglia, in both cultures. No differences were observed between wild-type and $\mathrm{C} /$ EBP $\beta$-null cultures in total cell density as assessed by automatic counting of Hoechst 33258-stained nuclei (Figure 1A), but a moderate increase in total cell number was induced by LPS and LPS+IFN $\gamma$. C/EBP $\beta$ absence did not affect microglial density as assessed by CD11bpositive cell counting (Figure 1B). Estimation of astrocytes number in these cultures is not trivial. Astrocytes are densely packed, almost all nuclei are surrounded by GFAP-positive filaments, and it is often difficult to discern whether a given nucleus belongs to a GFAP-positive cell or, in fact, the GFAP signal belongs to a neighbor astrocyte. We therefore analyzed total GFAP content by western blot as an indirect estimation of astroglial number and no differences were observed between wild-type and C/EBP $\beta$-null glial cultures (Figure 1D, E). Neither CD11b nor GFAP immunocytochemistry revealed differences between wild-type or C/ EBP $\beta$-null cultures in morphology of microglial cells or astrocytes, respectively (Figure 1C, F). These results indicate that wild-type and $\mathrm{C} / \mathrm{EBP} \beta$-null mixed glial cultures do not differ in total cell density or in proportions or morphology of their two major cell types, astrocytes and microglia.

\section{LPS and LPS+IFN $\gamma$ upregulate C/EBP $\beta$ in secondary mixed glial cultures}

In this study, we have used LPS and LPS+IFN $\gamma$ to study the role of $\mathrm{C} / \mathrm{EBP} \beta$ in glial activation in secondary cultures. The effects of both stimuli on C/EBP $\beta$ expression in glial cultures have not been compared before. As seen in Figure 2A-D, both LPS and LPS+IFN $\gamma$ induced strong increases in C/EBP $\beta$ mRNA levels $6 \mathrm{~h}$ after treatment, and in nuclear levels of both activating (Full/LAP) and inhibitory (LIP) C/EBP $\beta$ isoforms $24 \mathrm{~h}$ after treatment. The increases in C/EBP $\beta$ mRNA and protein induced by LPS and LPS+IFN $\gamma$ were of similar magnitude.

\section{Differential C/EBP $\beta$ activation is triggered by LPS and LPS + IFN $\gamma$}

Since the mRNA or protein levels of a transcription factor are of relative importance to study its functionality, we studied the DNA binding activity of C/EBP $\beta$ in LPSor LPS+IFN $\gamma$-treated glial cells. Electrophoretic mobility shift assays showed that binding of nuclear proteins to a DNA oligonucleotide containing the C/EBPs consensus sequence was increased by LPS and LPS+IFN $\gamma$ treatments (Figure 3A, lanes 1-3). Supershift experiments showed the presence of $C / E B P \beta$ in shifted complexes I to III (Figure 3A lanes 4-6). The specificity of the supershift is demonstrated by the lack of supershift elicited by the same concentration of IgG (Figure 3A lanes 7-9). This indicates that $C / E B P \beta$ is a key component of $\mathrm{C} /$ EBPs DNA binding complexes during LPS- and LPS + IFN $\gamma$-induced glial activation.

Next, we estimated the binding of C/EBP $\beta$ to the promoters of four major pro-inflammatory genes: nitric oxide synthase 2 (NOS2), IL-1 $\beta$, IL- 6 and TNF $\alpha$, in mixed glial cultures using a qChIP assay (Figure 3B). In untreated glial cultures, no specific binding of C/EBP $\beta$ was measurable in any of the four promoters analyzed. However, $2 \mathrm{~h}$ after LPS treatment, C/EBP $\beta$ binding was observed in the NOS2 promoter. Interestingly, in LPS + IFN $\gamma$-treated glial cultures C/EBP $\beta$ binding was observed in all four promoters analyzed and, in the case of the NOS2 promoter, C/EBP $\beta$ binding was significantly higher than in LPS-treated glial cultures (Figure 3B).

\section{C/EBP $\beta$ regulates pro-inflammatory gene expression in glial activation}

To study the involvement of C/EBP $\beta$ in the regulation of pro-inflammatory gene expression, mRNA levels of NOS2, IL-1 $\beta$, IL- 6 and TNF $\alpha$ were analyzed by qPCR in wild-type and C/EBP $\beta$-null cultures treated with LPS or LPS+IFN $\gamma$ for $6 \mathrm{~h}$. In wild-type cultures all four mRNAs were strongly upregulated by LPS. This effect was exacerbated by co-treatment with IFN $\gamma$ in the case of NOS2 (+92.3\%), but not in the case of IL-1 $\beta$, IL-6 or TNF $\alpha$ (Figure 4). In C/EBP $\beta$-null cultures LPS induced upregulation of IL-1 $\beta$, IL- 6 and TNF $\alpha$ mRNAs, which was similar to that observed in wild-type cultures. However, as expected from qChIP results, the LPS-induced increase in NOS2 mRNA levels was significantly lower in C/EBP $\beta$-null than in wild-type glial cultures $(-67.4 \%$, $\mathrm{p}<0.05)$. The pattern of gene expression induced by LPS+IFN $\gamma$ was more affected by lack of C/EBP $\beta$. Thus, LPS +IFN $\gamma$-induced mRNA levels of NOS 2 and IL-1 $\beta$ were significantly lower in C/EBP $\beta$-null than in wildtype cultures. TNF $\alpha$ and IL- 6 mRNA levels did not differ statistically between the two genotypes (Figure 4). In contrast to the pro-inflammatory gene pattern, mRNA levels of the anti-inflammatory cytokines IL-4 and transforming growth factor $\beta$ (TGF $\beta 1$ ) were not altered by LPS or LPS+IFN $\gamma$ treatments and no significant changes in IL-4 or TGF $\beta 1$ mRNA levels were observed between wild-type and $C / E B P \beta$-null glial cultures under any experimental condition (Figure 4).

\section{C/EBP $\beta$-null glial cultures show a marked reduction in NO production}

The important reduction in NOS2 mRNA levels in activated $C / E B P \beta$-null glial cultures prompted us to analyze 


\section{Total cell density}

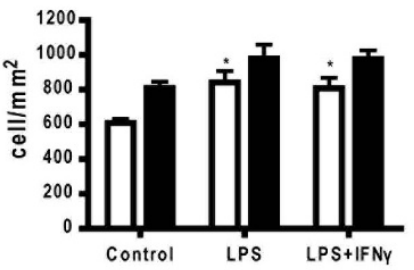

B

Microglia

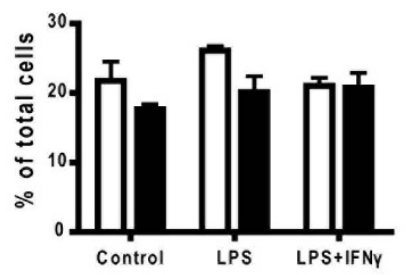

C

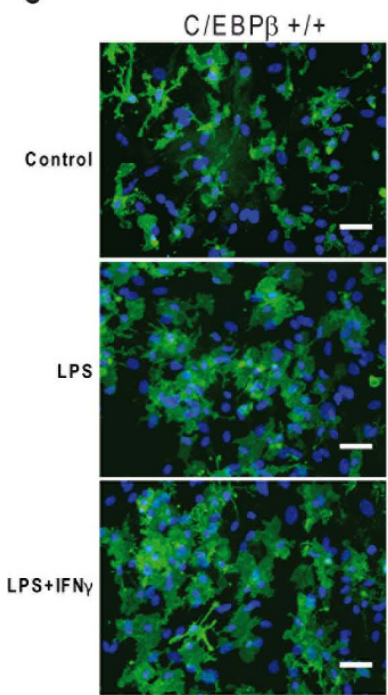

C/EBP $\beta$ - /.

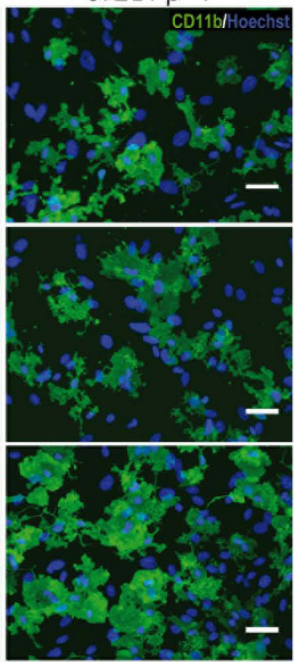
Astrocytes

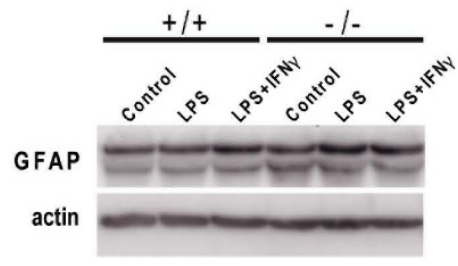

E

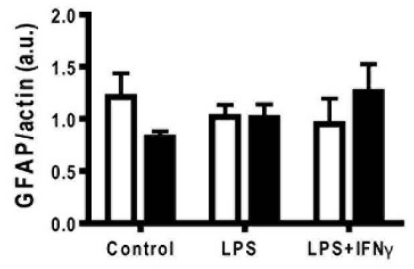

$\mathbf{F}$

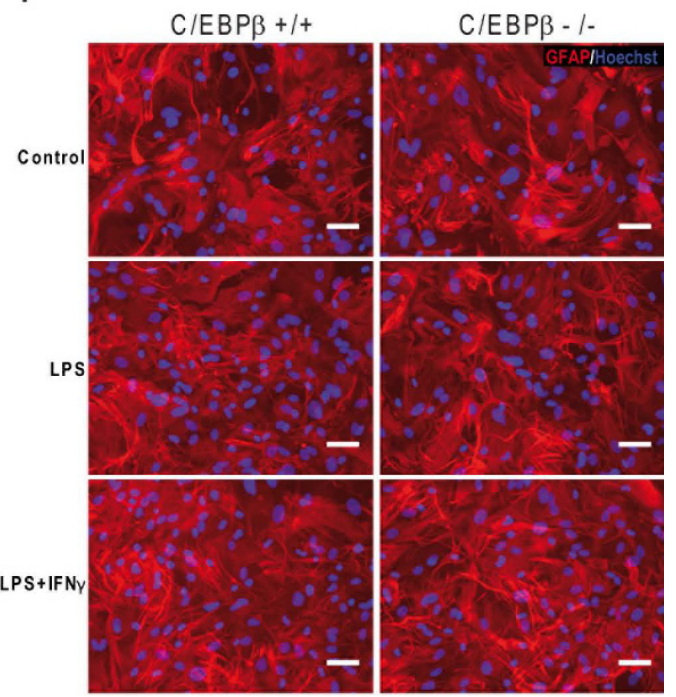

Figure 1 Basic characterization of $C / E B P \beta^{-/-}$mixed glial cultures. Secondary mixed glial cultures from C/EBP $\beta^{+/+}$(white bars) and C/EBP $\beta^{-/}$ (black bars) show similar total cell numbers and microglial density in control conditions and after $16 \mathrm{~h}$ of LPS or LPS+IFN $\gamma$. A. C/EBP ${ }^{+/+}$and C/ $\mathrm{EBP}^{-1-}$ total cell density was estimated by Hoechst-33258-positive nucleus counting. No significant differences were observed between genotypes. Wild-type cultures show a statistically significant increase of cell density after $16 \mathrm{~h}$ of LPS and LPS+IFN $\gamma$ treatment compared to control; C/EPB $\beta$-null cultures show no difference after treatments. Two-way ANOVA, followed by Bonferroni's test was applied. ${ }^{*} p<0.05$; compared to $C / E B P \beta^{+/+}$control. $(n=4)$. B. Microglia as a percentage of total cells was estimated by CD11b-positive cell counting in C/EBP ${ }^{+/+}$ and C/EBP $\beta^{-1-}$ cultures after $16 \mathrm{~h}$ treatments with LPS, LPS+IFN $\gamma$ or vehicle. Significant differences among treatments groups or genotypes are not observed. Two-way ANOVA, followed by Bonferroni's test was applied. $(n=4)$. C. Secondary mixed glial cultures were immunostained for CD11b (green). Nuclei are stained with Hoechst-33258 (blue). Microglial cell numbers were similar for C/EBP ${ }^{+/+}$and C/EBP $\beta^{-/}$Cultures. LPS and LPS+IFN $\gamma$ induced morphological changes in microglial cells in both genotypes. Bar $=50 \mu \mathrm{m}$. D. A representative western blot shows levels of GFAP in C/EBP $\beta^{+/+}$and C/EBP $\beta^{-/-}$mixed glial protein extracts $16 \mathrm{~h}$ after vehicle (control), LPS and LPS+IFN $\gamma$ treatments. $\beta$-Actin was used for normalization. E. Densitometric analysis was used to quantify GFAP protein levels versus $\beta$-actin in 4 independent western blots in arbitrary units (a.u.). Changes in GFAP protein levels are not observed. Two-way ANOVA, followed by Bonferroni's test was applied. $(n=4)$. F. Secondary mixed glial cultures were immunostained for GFAP (red) showing a confluent astrocytic layer. Overlapping of astroglial cell bodies makes counting very difficult and imprecise. No differences in astroglial morphology or density among genotypes are observed. Nuclei are stained with Hoechst33258 (blue). Bar $=50 \mu \mathrm{m}$. E. Lack of NOS2 expression in activated astrocytes. C/EBP $\beta^{+/+}$and C/EBP $\beta^{-/}$secondary mixed glial cultures were immunostained for GFAP (green) and NOS2 (red), and stained for Hoechst 33258 (blue), after 16 h of LPS+IFN $\gamma$ treatment. A marked reduction in number of NOS2-positive cells is seen in C/EBPß-null cultures. The representative merge images show clearly that NOS2-positive cells do not colocalize with GFAP-positive cells. Bar $=50 \mu \mathrm{m}$. 
A

mRNA

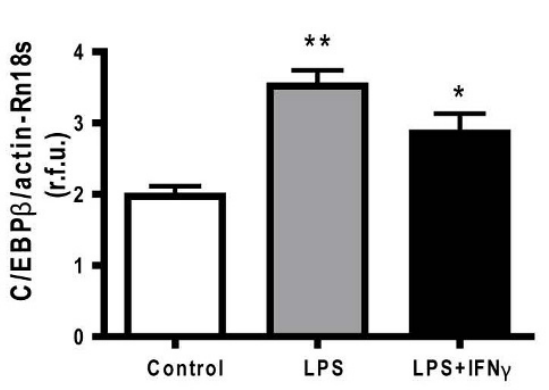

C

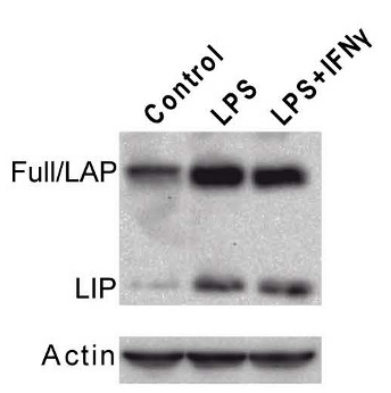

B

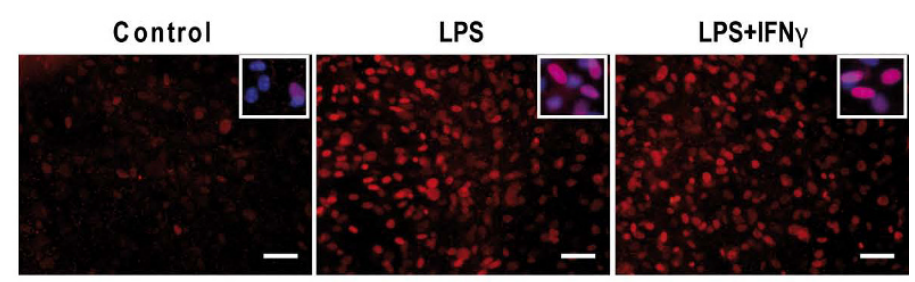

D

Protein

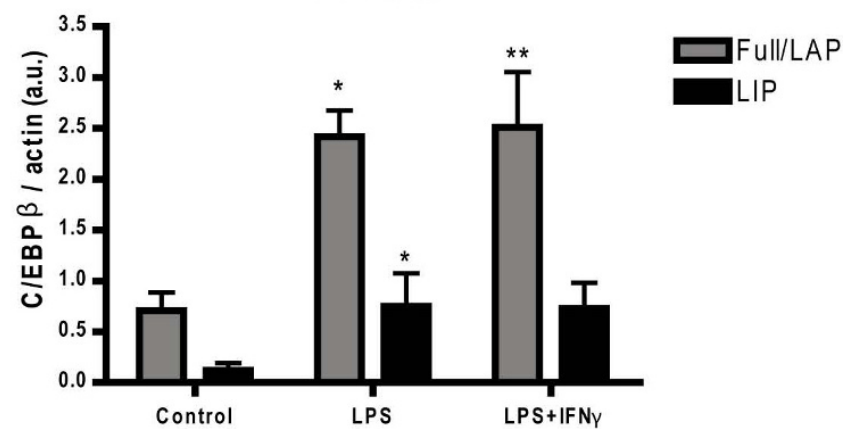

Figure 2 C/EBP $\beta$ expression in activated mixed glial cultures. Effect of $100 \mathrm{ng} / \mathrm{mL}$ LPS alone or in combination with $0.1 \mathrm{ng} / \mathrm{mL} \mathrm{IFN} \gamma$ on C/ EBP $\beta$ expression in secondary mixed glial cultures. A. C/EBP $\beta$ mRNA expression is upregulated in glial activation. Cultures were treated with LPS and LPS+IFN for $6 \mathrm{~h}$ and mRNA was analyzed by qPCR. Results are expressed as relative fold units (r.f.u.) of $\triangle \triangle C$ t values between C/EBP $\beta$ and actin + Rn18s as reference genes. One-way ANOVA followed by Dunnett's test is applied. ${ }^{*} p<0.05 ;{ }^{* *} p<0.01$ compared to control. $(n=3)$. B. LPS and LPS + IFN $\gamma(24 \mathrm{~h}$ ) increase nuclear C/EBPß immunostaining (red) in secondary mixed glial cultures. In the right upper corner, a detail shows overlapping between Hoechst 33258 nuclear staining and C/EBP $\beta$. Images are representative of 5 independent experiments. Bar $=50 \mu m$. C. A western blot shows levels of C/EBP $\beta$ in secondary mixed glial cultures treated with LPS or LPS + IFN $\gamma$ for 24 h. The C/EBP $\beta$ isoforms are identified as Full/LAP and LIP. $\beta$-Actin is used for normalization. This experiment was done 4 times with similar results. D. Full/LAP (grey bars) upregulation after LPS and LPS+IFN $\gamma$ is statistically significant compared to control. LIP (dashed bars) upregulation is statistically significant only for LPS treatment. One-way ANOVA, followed by Dunnett's test is applied. ${ }^{*} p<0.05$; ${ }^{* *} p<0.01$ compared to respective control. $(n=4-5)$

NOS2 protein levels by western blot and immunocytochemistry, and generation of NO by colorimetric detection of nitrites (Griess assay). In wild-type cultures NOS2 protein expression was induced by LPS and more markedly by LPS+IFN $\gamma$. In C/EBP $\beta$-null cultures LPSinduced NOS2 levels were not significantly different from wild-type whereas LPS+IFN $\gamma$-induced NOS2 protein levels were markedly reduced $(-77.4 \%, \mathrm{p}<0.0001)$ (Figure 5A, B). NO levels correlated well with the NOS2 protein data and a strongly significant attenuation in NO production induced by LPS+IFN $\gamma$ was seen in $\mathrm{C} /$ EBP $\beta$-null cultures (Figure 5C).

The reduction in LPS+IFN $\gamma$-induced NOS2 expression in $\mathrm{C} / \mathrm{EBP} \beta$-null glial cultures seen by western blot was confirmed by immunocytochemistry. We did not observe by immunocytochemistry any NOS2-positive cells in untreated cultures (not shown), whereas in LPS(not shown) and LPS+IFN $\gamma$-treated wild-type cultures, NOS2 immunoreactivity was observed in $14.0 \pm 3.6 \%$ of total cells (Figure 5D, E). The vast majority of NOS2positive cells in LPS+IFN $\gamma$-treated wild type mixed glial cultures also expressed CD11b $(99.3 \pm 1.4 \%$; $\mathrm{n}=11)$ and very rarely NOS2-positive cells expressed GFAP $(0.6 \pm 1.2 \% ; \mathrm{n}=11)$ indicating that in these conditions NOS2 expression in mouse cortical mixed glial cultures is predominantly microglial. In C/EBP $\beta$-null cultures the number of NOS2 cells was dramatically reduced after either LPS (not shown) or LPS+IFN $\gamma$ treatments (Figure $5 \mathrm{D}, \mathrm{E})$. As seen in Figure 5D, the reduction of NOS2positive cells could not be attributed to a reduction in microglial density.

\section{C/EBP $\beta$ deficiency in activated microglia abrogates neurotoxicity}

Activated microglia have strong neurotoxic potential [36]. The observations of reduced expression of proinflammatory mediators in LPS+IFN $\gamma$-activated C/EBP $\beta$ null glial cells, particularly microglia, prompted us to 
A

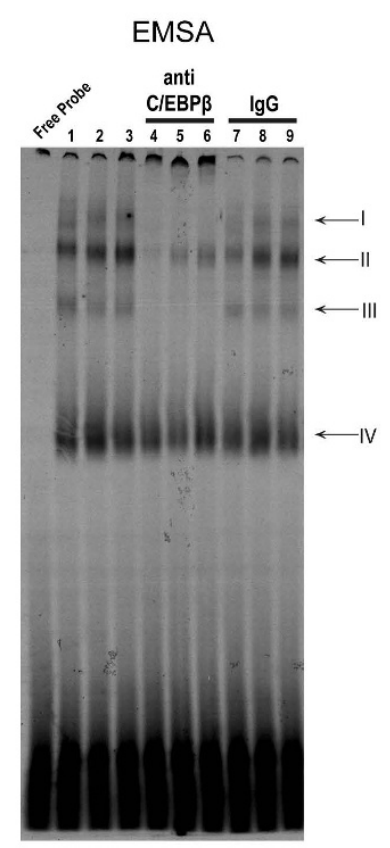

B ChIP anti-C/EBP $\beta$

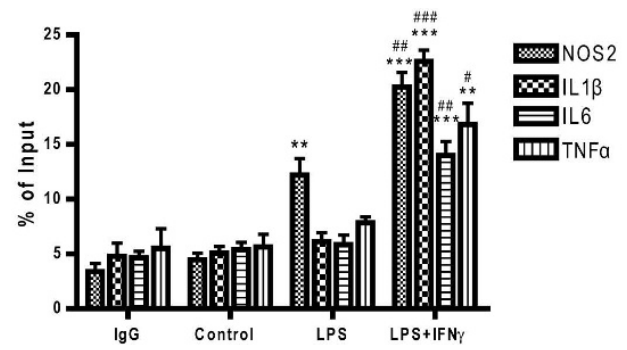

Figure 3 Binding of C/EBP $\beta$ to proinflammatory gene promoters in activated mixed glial cultures. A. C/EBP $\beta$ DNA binding activity was analyzed by gel shift and supershift assays. Nuclear proteins were extracted from secondary mixed glial cultures treated with vehicle (lanes 1, 4, 7), LPS (lanes 2, 5, 8) or LPS+IFN (lanes 3, 6, 9) for $2 \mathrm{~h}$. The first lane represents the probe without nuclear extract incubation (free probe). Arrows indicate four shifted complexes. Complex IV is a C/EBP $\beta$ independent complex. Lanes 1 to 3 show C/EBPs shifting complexes in wild type condition. Supershift with anti-C/EBP $\beta$ antibody (lanes 4 to 6 ) shows the presence of C/EBP $\beta$ in I-III complexes in all treatments. Rabbit lgG (lanes 7 to 9 ) is used as negative control for the supershift assay. This image is representative of four independent experiments. B. Quantitative analysis of C/EBP $\beta$ binding to NOS2, IL-1 $\beta$, IL-6 and TNF $\alpha$ promoters by qChIP in mixed glial cultures. The sequences and positions of every C/EBP $\beta$ binding site and the primers used for $\mathrm{qPCR}$ are found in table 2. IL-10 was used as positive control. The qChIP assay was carried out after $2 \mathrm{~h}$ of LPS, LPS+IFN $\gamma$ or vehicle (control) treatment. The lgG bars represent the means for lgG/Control, lgG/LPS and IgG/LPS+IFN $P C R$ values for each gene. Input refers to total DNA. $\%$ of input represents the percentage of qChIP/Input ratio. One-way ANOVA, followed by Bonferroni's multiple comparison test is applied. ${ }^{* *} p<0.01$; ${ }^{* * *} p<0.001$ compared to control. \#p $<0.05$; \#\#p $<0.01$; \#\#\# $<0.001$ compared to LPS. $(n=3)$ analyze whether the neurotoxic effects of LPS+IFN $\gamma$ activated microglia could be attenuated by $\mathrm{C} / \mathrm{EBP} \beta$ absence. To this aim, wild-type and C/EBP $\beta$-null microglial cells were isolated and co-cultured with wild-type neurons. No neuronal death was observed when neurons not co-cultured with microglia were treated with LPS+IFN $\gamma$ or when neuron/wild-type microglia co-cultures were treated with LPS alone (data not shown). In contrast, LPS+IFN $\gamma$ treatment of neuron/wild-type microglia co-cultures resulted in death of $51.2 \%$ of neurons, as estimated by MAP2/ABTS/ELISA (Figure 6). Interestingly, in neuron/C/EBP $\beta$-null microglia co-cultures treated with LPS+IFN $\gamma$, MAP2 immunoreactivity levels were equal to control levels (Figure 6) indicating that the neurotoxicity induced by LPS+IFN $\gamma$-treated microglia was completely abolished in the absence of $\mathrm{C} /$ EBP $\beta$. In this model, NO production plays a major role in the neurotoxicity elicited by activated microglia since the NOS2 inhibitor $1400 \mathrm{~W}(10 \mu \mathrm{M})$ completely abolished neuronal death in LPS+IFN $\gamma$-treated neuron/ microglia co-cultures (Gresa-Arribas et al, unpublished observations).

\section{Discussion}

The transcription factor C/EBP $\beta$ is expressed in glia but no direct evidence exists for its involvement in glial activation. In the present study we show that both LPS and LPS+IFN $\gamma$ upregulate C/EBP $\beta$ expression in mixed glial cultures to a similar extent. Both stimuli also induce $\mathrm{C} /$ EBP $\beta$ binding to proinflammatory gene promoters but this binding is stronger when induced by LPS+IFN $\gamma$. Lack of C/EBP $\beta$ results in attenuated expression of proinflammatory genes and, again, this effect is more pronounced when glial cells are activated with LPS + IFN $\gamma$ than when LPS alone is the activating stimulus. Finally, we describe for the first time that neurotoxicity elicited by LPS+IFN $\gamma$-treated microglial cells is completely abrogated by lack of C/EBP $\beta$.

In this study we have used mixed glial cultures composed mainly of astrocytes and microglia. This culture system is our model of choice to study glial activation because it allows cross-talk between the two cell types, which is extremely important in glial activation [37]. Working with astrocytes or microglia in isolation may yield misleading results and there are numerous examples of astroglial or microglial responses that are markedly affected by the absence of the other cell type [37-39]. Regarding C/EBP $\beta$, we have previously shown in experiments with mixed glial and astroglial- or microglial-enriched cultures that, upon activation, C/EBP $\beta$ is primarily expressed by microglia with a lesser upregulation in astrocytes [24]. This suggests that the data here reported on $C / E B P \beta$ in glial activation mainly reflects $C / E B P \beta$ changes in microglia although part of the 


\section{$\mathrm{C} / \mathrm{EBP} \beta+/+\square \mathrm{C} / \mathrm{EBP} \beta-/-$}

\section{NOS2}
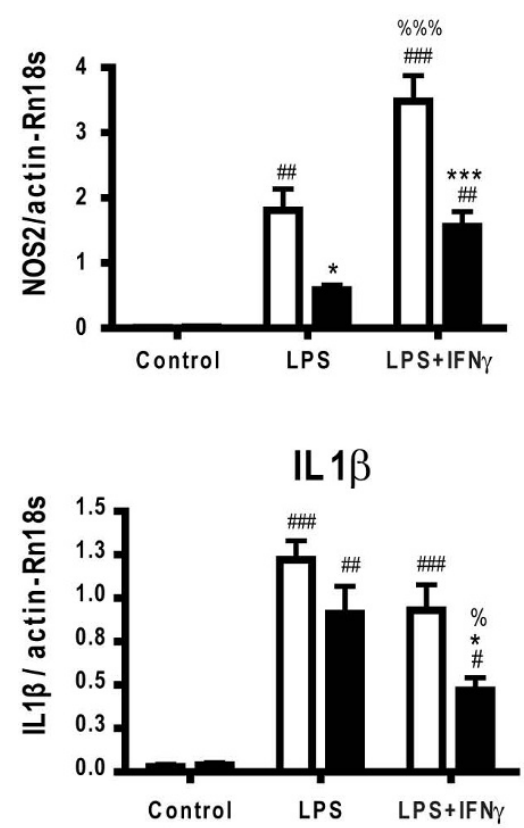

IL 4

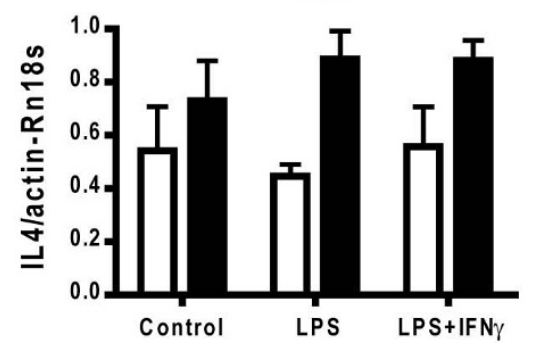

IL 6

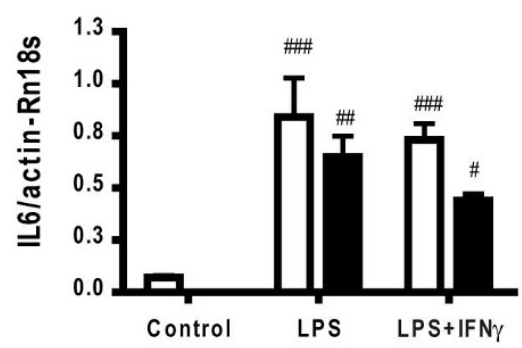

TNF $\alpha$

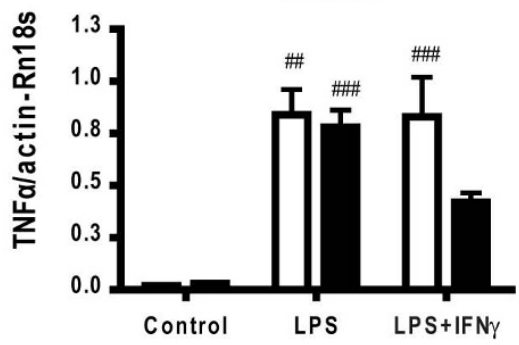

TGF $\beta 1$

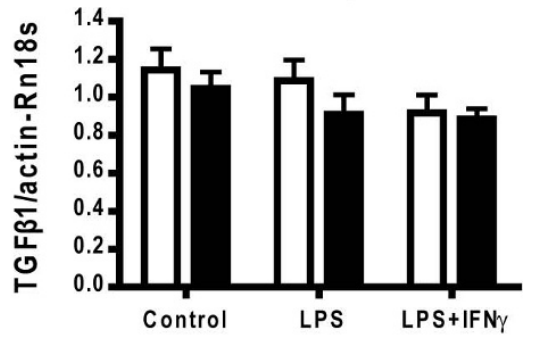

Figure 4 Reduced proinflammatory gene expression in C/EBP $\beta^{-/-}$mixed glial cultures. Expression of pro-inflammatory (NOS2, IL-1 $\beta$, IL- 6 and TNF $\alpha$ ) and anti-inflammatory (IL-4 and TGF $\beta 1$ ) genes in C/EBP $\beta^{+/+}$(white bars) and C/EBP ${ }^{-/}$(black bars) mixed glial cultures. Cultures were treated with LPS or LPS+IFN $\gamma$ for $6 \mathrm{~h}$ and then mRNA levels were analyzed by qPCR. In wild type cultures LPS and LPS+IFN induce expression of the four pro-inflammatory genes studied but do not affect mRNA levels of the anti-inflammatory genes IL-4 and TGF $\beta$. Absence of C/EBP $\beta$ results in significant decreases in LPS-induced expression of NOS2 and in LPS+IFNy-induced expression of NOS2 and IL-1 $1 \beta$. Results are expressed as relative fold units of $\triangle \Delta C t$ value between gene of interest and actin + Rn18s as reference genes. Two-way ANOVA, followed by Bonferroni's test was applied. ${ }^{*} p<0.05,{ }^{* * *} p<0.001$ compared to respective C/EBP $\beta^{+/+}$condition. ${ }^{\#} p<0.05 ;{ }^{\# \#} p<0.01$; ${ }^{\# \# \# ~} p<0.001$ compared to respective control. ${ }^{\%} \mathrm{p}<0.05 ;{ }^{\%} \% \mathrm{p}<0.001$ compared to respective LPS condition.

observed effects could be of astroglial origin. However, in the case of the effects of C/EBP $\beta$ absence on NOS2 expression and neurotoxicity, the observed effects are clearly microglial, as shown by the microglial localization of NOS2 immunoreactivity and by the use of isolated microglia, respectively.

Most protocols to prepare primary mixed glial cultures from rodents use pools of tissue from several neonates, generally one or two litters. Since C/EBP $\beta$ females are sterile [40] litters of $\mathrm{C} / \mathrm{EBP} \beta$-null neonates cannot be obtained. Furthermore, approximately $50 \%$ of $\mathrm{C} /$ EBP $\beta$-null pups die perinatally [28] which favors the use of late embryos instead of neonates to ensure a maximum number of available C/EBP $\beta$-null mice. Therefore, we established for this study a new protocol of secondary mixed glial cultures by subculturing primary glial cultures prepared from the cerebral cortex of a single E19-E20 embryo. The use of secondary cultures was particularly suitable for this project because we could prepare mixed glial cultures that were very similar to 


\section{$\mathrm{C} / \mathrm{EBP} \beta+/+\square \mathrm{C} / \mathrm{EBP} \beta-/-$}

B

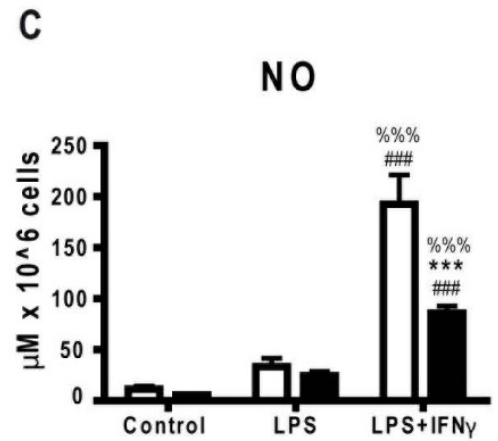

D

\section{Protein}

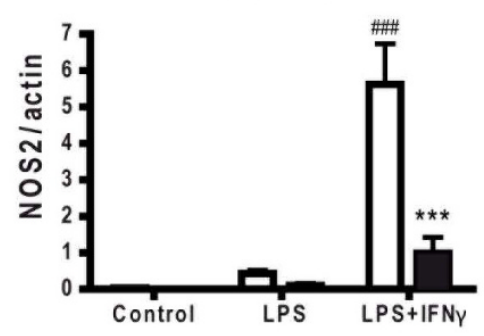

C/EBP $\beta-/-$
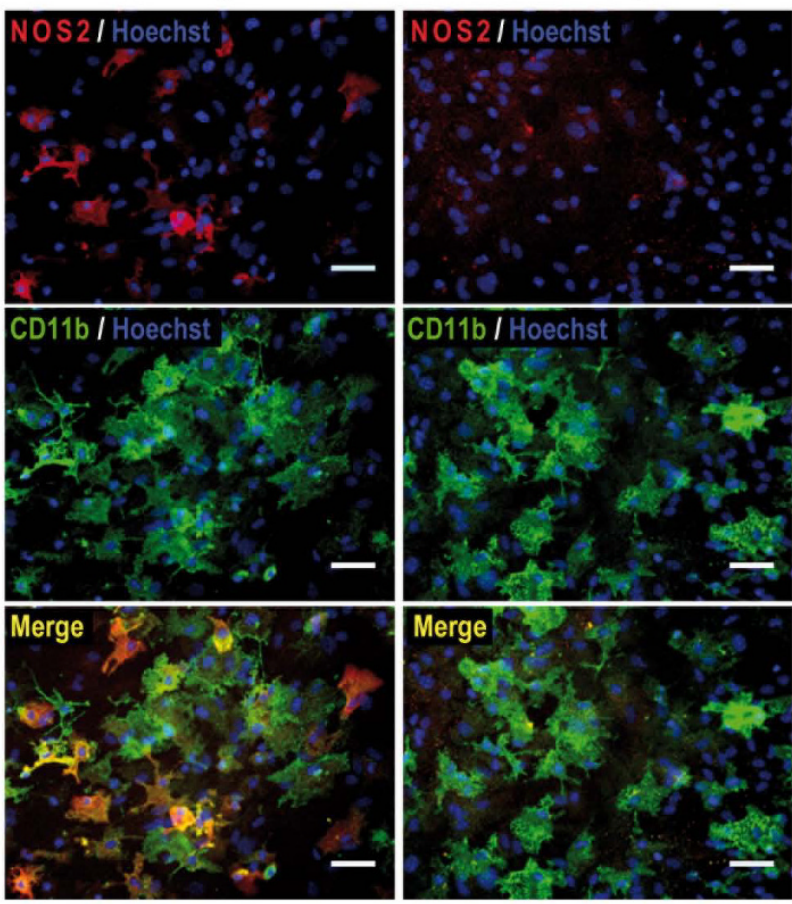
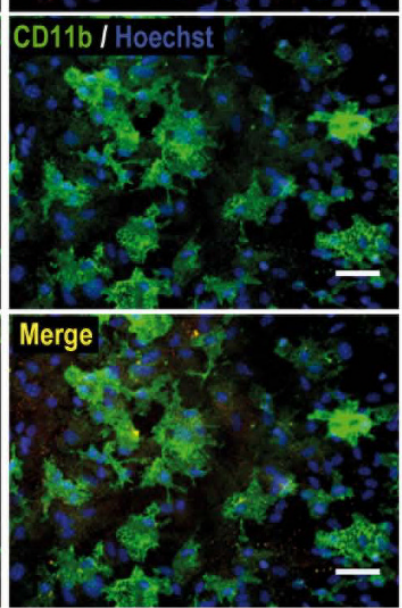

E
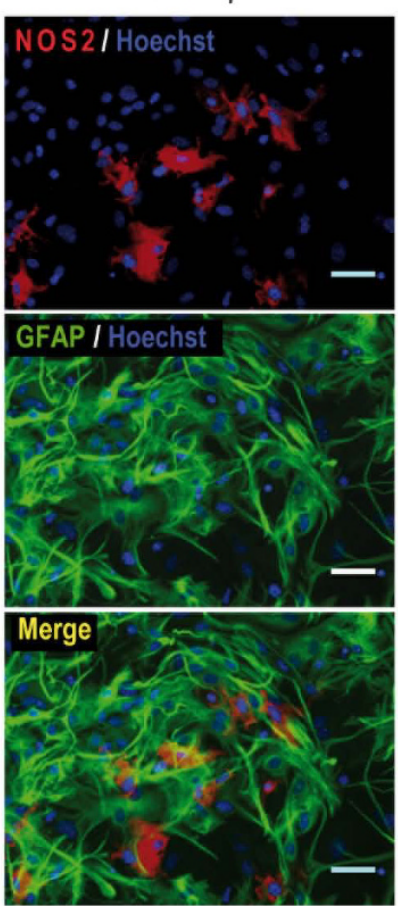

\section{C/EBP $\beta$-/-}
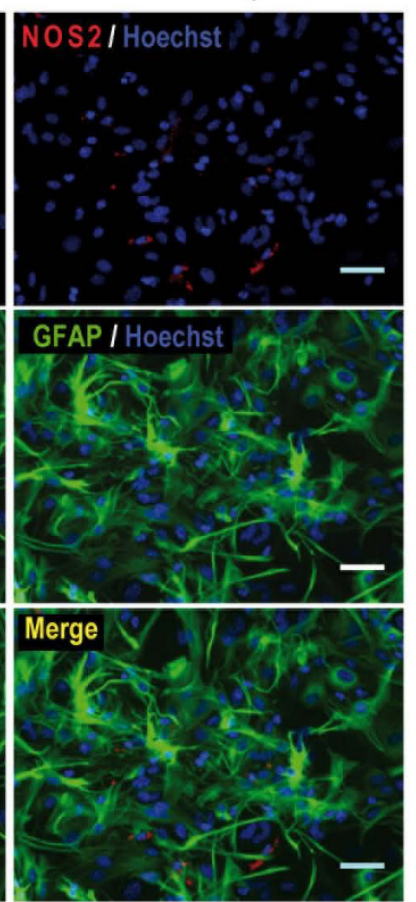

Figure 5 Absence of C/EBP $\beta$ dramatically decreases microglial NOS2 protein expression and NO production in activated mixed glial cultures. A. NOS2 protein levels in total protein extracts from mixed glial cultures were analyzed by western blot, followed by densitometry. Data is expressed as NOS2 versus $\beta$-actin band intensities. Cultures were treated for $16 \mathrm{~h}$ with LPS, LPS+IFN or vehicle. In C/EBP $\beta^{+/+}$Cultures (white bars) NOS2 protein levels were detected after LPS treatment, but LPS+IFN induced a clear upregulation, in agreement with mRNA expression levels. In C/EBP ${ }^{-/-}$mixed glial cultures (black bars), NOS2 protein levels decreased in LPS and LPS+IFN $\gamma$ compared to C/EBP $\beta^{+/+}$ cultures. Two-way ANOVA, followed by Bonferroni's test was applied. ${ }^{* *} \mathrm{p}<0.001$ compared with C/EBP $\beta^{+/+}$condition. ${ }^{\# \# \#} \mathrm{p}<0.001$ compared with respective control condition. $(n=5)$. A representative western blot is shown in B. C. NO production is decreased in activated C/EBP ${ }^{-/}$glial cultures. NO levels were measured by colorimetric analysis $48 \mathrm{~h}$ after treatments and normalized per cell number. Values are reported as micromolar concentration $\times 10^{6}$ cells. NO levels in C/EBPB ${ }^{+/+}$(white bars) cultures were upregulated after LPS and LPS+IFN $\gamma$ treatments compared to controls. In C/EBP ${ }^{-1}$ glial cultures (black bars), NO production is reduced in LPS+IFN $\gamma$ treatment compared to wild-type NO levels. Two-way ANOVA, followed by Bonferroni's test was applied. ${ }^{* *} \mathrm{p}<0.001$ compared to C/EBP ${ }^{+/+}$condition. ${ }^{\# \# \#} \mathrm{p}<0.001$ compared to respective control condition. ${ }^{\% \%} \% \mathrm{p}<0.001$ compared to respective LPS condition. $(n=7-9)$. D. NOS2 is expressed by activated microglia. C/EBP $\beta^{+/+}$and C/ $\mathrm{EBP \beta}^{-1-}$ secondary mixed glial cultures were immunostained for CD11b (green) and NOS2 (red), and stained for Hoechst 33258 (blue) after $16 \mathrm{~h}$ of LPS+IFNy treatment. The C/EBP $\beta^{+/+}$merged image shows colocalization of NOS2-positive cells and CD11b-positive cells. Bar $=50 \mu \mathrm{m}$. 


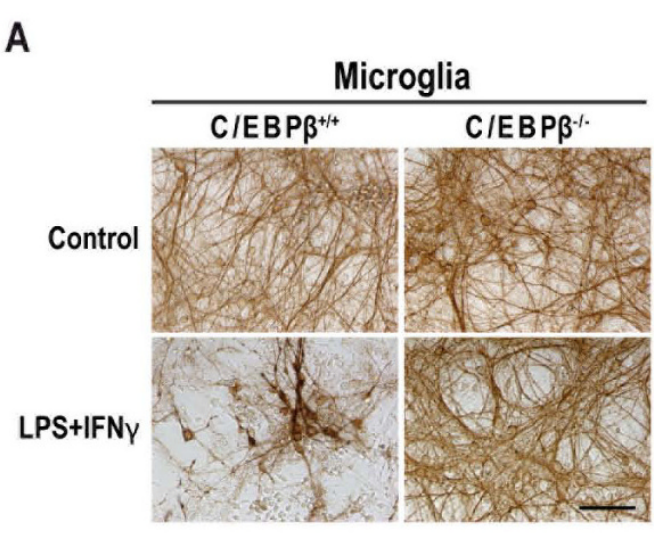

B

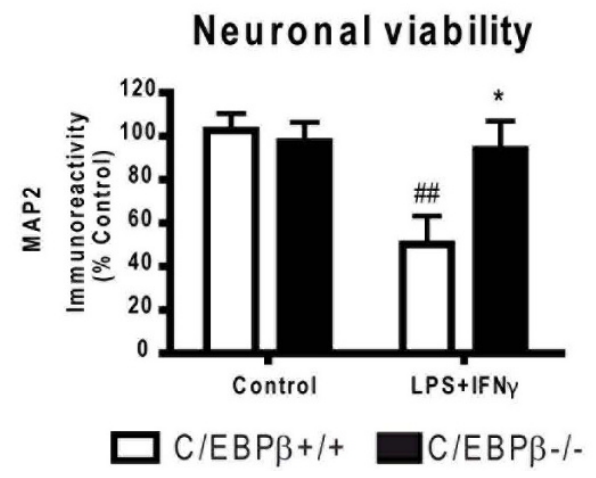

Figure 6 Lack of C/EBP $\beta$ in activated microglia completely abolishes the neurotoxic effects of activated microglia in neuronal-microglial co-cultures. A. MAP2 immunostaining of wildtype neurons co-cultured with C/EBP $\beta^{+/+}$or $\mathrm{C} / E \mathrm{EP} \beta^{-/-}$microglia was performed $48 \mathrm{~h}$ after LPS+IFN $\gamma$ treatment. MAP2 staining shows a clear decrease of network fibres caused by activated C/EBP $\beta^{+/+}$ microglia, but not by $\mathrm{C} / \mathrm{EBP} \beta^{-1-}$ microglia or by vehicle-treated microglia. Images are representative of 5 independent experiments. $($ Bar $=100 \mu \mathrm{m})$. B. Evaluation of neuronal viability by MAP2/ABTS/ ELISA assay $48 \mathrm{~h}$ after treatment with LPS+IFN $\gamma$ or vehicle (control). Results are presented as \% of MAP2 immunostaining in control cultures. Treatment with LPS+IFN $\gamma$ reduces MAP2 immunostaining in neurons cocultured with $\mathrm{C} / \mathrm{EBP} \beta^{+/+}$microglia, but not with $\mathrm{C} /$ $\mathrm{EBP}^{-/-}$microglia. Two-way ANOVA, followed by Bonferroni's test was applied. ${ }^{\# \#} p<0.01$ compared with C/EBP $\beta^{+/+}$control; ${ }^{*} p<0.05$ compared to C/EBP $\beta^{+/+}$LPS+IFN $\gamma$. $(n=5)$.

primary cultures in terms of cell density and proportions with a more-than-2-fold higher yield. Besides, the use of siblings eliminates any genetic background effect. Altogether, this makes the use of secondary mixed glial cultures from a single embryo or neonate a useful approach when working with mouse strains of compromised fertility.

LPS is a toll-like receptor 4 agonist that induces marked changes in gene expression in astrocytes and microglia [1]. The combination of LPS, a pathogen factor, with IFN $\gamma$, a host factor, potentiates some of the
LPS-induced effects [41]. Here we report for the first time a proper comparison between LPS and LPS+IFN $\gamma$ effects on C/EBP $\beta$ and on pro-inflammatory markers in glial cells. We have observed that both LPS and LPS + IFN $\gamma$ induce similar increases in C/EBP $\beta$ mRNA and protein levels as well as in DNA binding. Time-course analyses have revealed that upregulation of the C/EBP $\beta$ activating isoforms Full/LAP often precedes upregulation of the inhibitory isoform LIP $[21,24,42]$. When a single time-point is analyzed, as in the present study, the simultaneous increase in activating and inhibitory C/EBP $\beta$ isoforms is a common observation. EMSA analysis with supershift experiments showed the presence of C/EBP $\beta$ in bands I, II and III. These bands may contain different C/EBP $\beta$ isoforms (Full, LAP or LIP) with various post-translational modifications (phosphorylation, SUMOylation or acetylation has been described [43]). It is likely that some of these bands contain more than one complex (e.g. band II since it is only partially supershifted by anti-C/EBP $\beta$ ) and that some of these complexes contain other transcription factors, p65$\mathrm{NF} \kappa \mathrm{B}[44]$ and $\mathrm{C} / \mathrm{EBP} \delta[45,46]$ being two of the most likely candidates to form complexes with $C / E B P \beta$ in neuroinflammation. An extensive biochemical analysis would be necessary to characterize the transcriptional $\mathrm{C} / \mathrm{EBP} \beta$ complexes in activated glial cells.

This study shows for the first time in glial cells an analysis of mRNA levels for the pro-inflammatory genes NOS2, IL- $1 \beta$, IL- 6 and TNF $\alpha$, comparing LPS and LPS + IFN $\gamma$ as activating stimuli. In this model, IFN $\gamma$ alone did not trigger any effect (data not shown) whereas LPS and LPS+IFN $\gamma$ upregulated all four pro-inflammatory genes analyzed. LPS and LPS+IFN $\gamma$ increased expression of IL- $1 \beta$, IL- 6 and TNF $\alpha$ to the same extent, as reported for macrophages [47], whereas LPS-induced upregulation of NOS2 was markedly potentiated by cotreatment with IFN $\gamma$, in agreement with previous observations in microglia [48] and macrophages [19]. Even though transcriptional levels of cytokine genes in LPS-treated glial cultures are not modulated by cotreatment with IFN $\gamma$, their promoter regions undergo a remodeling of transcriptional complex as proved by qChIP assay. mRNA analysis showed that absence of C/EBP $\beta$ does not affect LPS-induced upregulation of the three cytokines, in agreement with absence of C/EBP $\beta$ binding to IL- $1 \beta$, IL- 6 or TNF $\alpha$ promoters in LPS-treated glial cultures, as seen by qChIP. Although we cannot exclude the presence of $C / E B P \beta$ in other promoter regions, because we focused our promoter analysis on the C/EBP $\beta$ consensus sequence most proximal to the translation start site, these data strongly suggest that $\mathrm{C} / \mathrm{EBP} \beta$ does not participate in the LPS-induced expression of these three genes in the present model. It may seem contradictory that strong C/EBP $\beta$ binding to IL-1 $\beta$, IL- 6 and TNF $\alpha$ 
promoters was induced by LPS+IFN $\gamma$, but not by LPS alone, whereas the levels of these cytokine mRNAs were similar after treatment with either LPS or LPS+IFN $\gamma$. In our opinion, this indicates that different sets of transcription factors act on these promoters after LPS or LPS+IFN $\gamma$ treatment or, in other words, that there is IFN $\gamma$-induced chromatin remodeling on these promoters [49]. This is also suggested by the qPCR data showing that LPS+IFN $\gamma$-induced expression of IL- $1 \beta$ is reduced in the absence of C/EBP $\beta$, and that there is also a tendency toward reduced expression of TNF $\alpha$ and IL- 6 . These data demonstrate for the first time that $C / E B P \beta$ plays a role in transactivation of pro-inflammatory cytokine genes in glial cells induced by LPS+IFN $\gamma$ but not by LPS alone.

In our glial activation model, the NOS2 gene shows a different transcription pattern when compared with the pro-inflammatory cytokines. On the one hand, as mentioned before, LPS-induced NOS2 expression is potentiated by co-treatment with IFN $\gamma$. On the other hand, C/EBP $\beta$ binding to the NOS2 promoter is already seen after LPS treatment alone and, interestingly, this binding is potentiated by IFN $\gamma$ treatment. As observed in macrophage cell lines, IFN $\gamma$ can trigger C/EBP $\beta$ phosphorylation, modulating its capacity to form transcriptional complexes with p300 [50] or Med1 [51]. Also, IFN $\gamma$ can promote C/EBP $\beta$ DNA binding activity to IFN-stimulated regulatory elements (ISREs) which we have found tightly associated with $\mathrm{C} / \mathrm{EBP} \beta$ consensus sequences on the mouse NOS2 promoter (unpublished observations). Finally, both LPS- and LPS+IFN $\gamma$-induced increases in NOS2 expression are attenuated in the absence of $\mathrm{C} /$ $\mathrm{EBP} \beta$. These findings suggest that $\mathrm{C} / \mathrm{EBP} \beta$ plays a functional role both in LPS-induced NOS2 expression and in the potentiation of this effect elicited by IFN $\gamma$. In accordance with the multiple stage glial activation model [52], we can hypothesize that LPS alone activates the glia, but that only with a host warning signal, such as IFN $\gamma$, are glia totally committed to a hyper-reactive phenotype. We propose that C/EBP $\beta$ could trigger this shift through the executive phase of glial activation.

The hypothesis of a pathogenic role for exacerbated glial activation, particularly activation of microglia, is based on the known in vitro neurotoxic effects of activated microglia [53,54], on the protective effects of antiinflammatory treatments or genetic modifications in animal models of neurodegenerative disorders $[55,56]$ and on epidemiological data [57-59]. Since we have shown in this study that C/EBP $\beta$ deficiency attenuates expression of potentially neurotoxic pro-inflammatory mediators but not that of anti-inflammatory cytokines, we were interested to test the hypothesis that C/EBP $\beta$ plays a key role in the induction of detrimental effects by microglial activation. Reduced neuronal damage after ischemic [26] or excitotoxic insults [27] has been observed in $\mathrm{C} / \mathrm{EBP} \beta$-null mice. Even though $\mathrm{C} / \mathrm{EBP} \beta$ expression has been reported in activated glial cells [22-24], C/EBP $\beta$ is known to be also expressed in the adult mouse by neurons [60] and peripheral cells [16]. Consequently, the neuroprotective effect observed in $\mathrm{C} /$ $E B P \beta$-null mice could be mediated by lack of $C / E B P \beta$ in any of these cells. We show here that the neurotoxicity elicited by activated wild-type microglial cells co-cultured with wild-type neurons is completely abolished by the absence of C/EBP $\beta$ specifically in microglia. This strongly supports a role of $\mathrm{C} / \mathrm{EBP} \beta$ in the regulation of potentially neurotoxic effects of microglia and suggests that the neuroprotective effects of total C/EBP $\beta$ absence in vivo $[26,27]$ are due to microglial C/EBP $\beta$ deficiency. Specific microglial C/EBP $\beta$ deletion would be very informative to clarify the role of microglial $\mathrm{C} / \mathrm{EBP} \beta$ in neurodegeneration in in vivo models of neurological disease.

\section{Conclusions}

In summary, this study shows that LPS and LPS+IFN $\gamma$ induce expression of C/EBP $\beta$ in mixed glial cultures, and both stimuli also induce differential binding of $\mathrm{C} /$ EBP $\beta$ to proinflammatory gene promoters. A functional role for $\mathrm{C} / \mathrm{EBP} \beta$ in glial activation is demonstrated by the attenuated gene expression and abrogation of neurotoxicity in microglial cells devoid of $\mathrm{C} / \mathrm{EBP} \beta$. Altogether, these findings point to $C / E B P \beta$ as a key transcription factor in the molecular reprogramming that occurs in microglial activation and suggest that $C / E B P \beta$ is a possible therapeutic target to ameliorate neuronal damage of neuroinflammatory origin.

\section{List of abbreviations}

ABTS: 2, 3'-azinobisethylbenzothiazoline-6-sulphonic acid; ANOVA: Analysis of variance; C/EBP $\beta$ : CCAAT/enhancer binding protein $\beta$; DIV: Days in vitro; GFAP: Glial fibrillary acidic protein; HRP: Horseradish peroxidase; IFNY: Interferon Y; IL: Interleukin; LPS: Lipopolysaccharide; NOS2: NO synthase-2; qChiP: Quantitative chromatin immunoprecipitation; qPCR: Quantitative real time PCR; RT: Room temperature; TGF $\beta 1$ : Transforming growth factor $\beta 1$; TNFa: Tumour necrosis factor-a

\section{Acknowledgements}

We thank Colleen Croniger and Valeria Poli for the generous gift of C/EBP $\beta$ knockout mice, Teresa Domingo and colleagues at animal facilities of the School of Pharmacy (University of Barcelona) for the professional care of C/ EBP $\beta$ knockout mice and Tony Valente for technical assistance. Marco Straccia and Nuria Gresa-Arribas are recipients of JAE contracts from CSIC. Guido Dentesano is a recipient of IDIBAPS fellowship contract. This study was supported by grants PI07/455, PI08/1396 and P10/378 from the Instituto de Salud Carlos III, Spain.

\section{Author details}

'Biochemistry and Molecular Biology Unit, School of Medicine, University of Barcelona, IDIBAPS, Barcelona, Spain. ${ }^{2}$ Department of Brain Ischemia and Neurodegeneration, IIBB-CSIC, IDIBAPS, Barcelona, Spain.

\section{Authors' contributions}

MS carried out most experiments and drafted the manuscript. NGA carried the experiments involving neuron/microglia cocultures. GD carried out the 
qChIP experiments. AEO set the C/EBP $\beta$-null colony and carried out the preliminary experiments. JMT participated in the preparation of primary cultures. JSe participated in immunocytochemistry experiments. CS designed and participated in the neuron/microglia cocultures experiments and participated in the statistical analysis. JSa conceived and coordinated the study and drafted the manuscript. All authors critically revised and approved the final manuscript.

\section{Competing interests}

The authors declare that they have no competing interests.

Received: 10 August 2011 Accepted: 10 November 2011 Published: 10 November 2011

\section{References}

1. Michelucci A, Heurtaux T, Grandbarbe L, Morga E, Heuschling P: Characterization of the microglial phenotype under specific proinflammatory and anti-inflammatory conditions: Effects of oligomeric and fibrillar amyloid-beta. J Neuroimmunol 2009, 210:3-12.

2. Cho IH, Hong J, Suh EC, Kim JH, Lee H, Lee JE, Lee S, Kim CH, Kim DW, Jo EK, Lee KE, Karin M, Lee SJ: Role of microglial IKKbeta in kainic acidinduced hippocampal neuronal cell death. Brain 2008, 131:3019-3033.

3. Kaltschmidt B, Widera D, Kaltschmidt C: Signaling via NF-kappaB in the nervous system. Biochim Biophys Acta 2005, 1745:287-299.

4. Kwon D, Fuller AC, Palma JP, Choi IH, Kim BS: Induction of chemokines in human astrocytes by picornavirus infection requires activation of both AP-1 and NF-kappa B. Glia 2004, 45:287-296.

5. Kim OS, Park EJ, Joe EH, Jou I: JAK-STAT signaling mediates gangliosidesinduced inflammatory responses in brain microglial cells. J Biol Chem 2002, 277:40594-40601

6. Wang X, Li C, Chen Y, Hao Y, Zhou W, Chen C, Yu Z: Hypoxia enhances CXCR4 expression favoring microglia migration via HIF-1alpha activation. Biochem Biophys Res Commun 2008, 371:283-288.

7. Zhang W, Petrovic JM, Callaghan D, Jones A, Cui H, Howlett C, Stanimirovic D: Evidence that hypoxia-inducible factor-1 (HIF-1) mediates transcriptional activation of interleukin-1beta (IL-1beta) in astrocyte cultures. J Neuroimmunol 2006, 174:63-73.

8. Friedle SA, Brautigam VM, Nikodemova M, Wright ML, Watters JJ: The P2X7Egr pathway regulates nucleotide-dependent inflammatory gene expression in microglia. Glia 2011, 59:1-13.

9. ladecola C, Salkowski CA, Zhang F, Aber T, Nagayama M, Vogel SN, Ross ME: The transcription factor interferon regulatory factor 1 is expressed after cerebral ischemia and contributes to ischemic brain injury. J Exp Med 1999, 189:719-727.

10. Drew PD, Xu J, Storer PD, Chavis JA, Racke MK: Peroxisome proliferatoractivated receptor agonist regulation of glial activation: relevance to CNS inflammatory disorders. Neurochem Int 2006, 49:183-189.

11. Lee JM, Li J, Johnson DA, Stein TD, Kraft AD, Calkins MJ, Jakel RJ, Johnson JA: Nrf2, a multi-organ protector? FASEB J 2005, 19:1061-1066.

12. Shih $A Y$, Johnson DA, Wong G, Kraft AD, Jiang L, Erb H, Johnson JA, Murphy $\mathrm{TH}$ : Coordinate regulation of glutathione biosynthesis and release by Nrf2-expressing glia potently protects neurons from oxidative stress. J Neurosci 2003, 23:3394-3406.

13. Ossipow $V$, Descombes $P$, Schibler U: CCAAT/enhancer-binding protein mRNA is translated into multiple proteins with different transcription activation potentials. Proc Natl Acad Sci USA 1993, 90:8219-8223.

14. Welm AL, Timchenko NA, Darlington GJ: C/EBPalpha regulates generation of C/EBPbeta isoforms through activation of specific proteolytic cleavage. Mol Cell Biol 1999, 19:1695-1704.

15. Greenbaum LE, Li W, Cressman DE, Peng Y, Ciliberto G, Poli V, Taub R: CCAAT enhancer- binding protein beta is required for normal hepatocyte proliferation in mice after partial hepatectomy. J Clin Invest 1998, 102:996-1007.

16. Ramji DP, Foka P: CCAAT/enhancer-binding proteins: structure, function and regulation. Biochem $J$ 2002, 365:561-575.

17. Poli V: The role of C/EBP isoforms in the control of inflammatory and native immunity functions. J Biol Chem 1998, 273:29279-29282.

18. Caivano M, Gorgoni B, Cohen P, Poli V: The induction of cyclooxygenase-2 mRNA in macrophages is biphasic and requires both CCAAT enhancerbinding protein beta (C/EBP beta) and C/EBP delta transcription factors. J Biol Chem 2001, 276:48693-48701.
19. Lowenstein CJ, Alley EW, Raval P, Snowman AM, Snyder SH, Russell SW, Murphy WJ: Macrophage nitric oxide synthase gene: two upstream regions mediate induction by interferon gamma and lipopolysaccharide. Proc Natl Acad Sci USA 1993, 90:9730-9734.

20. Reddy ST, Wadleigh DJ, Herschman HR: Transcriptional regulation of the cyclooxygenase-2 gene in activated mast cells. J Biol Chem 2000, 275:3107-3113.

21. Bradley MN, Zhou L, Smale ST: C/EBPbeta regulation in lipopolysaccharide-stimulated macrophages. Mol Cell Biol 2003, 23:4841-4858.

22. Cardinaux JR, Allaman I, Magistretti PJ: Pro-inflammatory cytokines induce the transcription factors C/EBPbeta and C/EBPdelta in astrocytes. Glia 2000, 29:91-97.

23. Cardinaux JR, Magistretti PJ: Vasoactive intestinal peptide, pituitary adenylate cyclase-activating peptide, and noradrenaline induce the transcription factors CCAAT/enhancer binding protein (C/EBP)-beta and C/EBP delta in mouse cortical astrocytes: involvement in CAMPregulated glycogen metabolism. J Neurosci 1996, 16:919-929.

24. Ejarque-Ortiz A, Medina MG, Tusell JM, Perez-Gonzalez AP, Serratosa J, Saura J: Upregulation of CCAAT/enhancer binding protein beta in activated astrocytes and microglia. Glia 2007, 55:178-188.

25. Perez-Capote K, Saura J, Serratosa J, Sola C: Expression of C/EBPalpha and $\mathrm{C} /$ EBPbeta in glial cells in vitro after inducing glial activation by different stimuli. Neurosci Lett 2006, 410:25-30.

26. Kapadia R, Tureyen K, Bowen KK, Kalluri H, Johnson PF, Vemuganti R: Decreased brain damage and curtailed inflammation in transcription factor CCAAT/enhancer binding protein beta knockout mice following transient focal cerebral ischemia. J Neurochem 2006, 98:1718-1731.

27. Cortes-Canteli M, Luna-Medina R, Sanz-Sancristobal M, Alvarez-Barrientos A, Santos A, Perez-Castillo A: CCAAT/enhancer binding protein beta deficiency provides cerebral protection following excitotoxic injury. J Cell Sci 2008, 121:1224-1234.

28. Screpanti I, Romani L, Musiani P, Modesti A, Fattori E, Lazzaro D, Sellitto C, Scarpa S, Bellavia D, Lattanzio G, Bistoni F, Frati L, Cortese R, Gulino A, Ciliberto G, Constantini F, Poli V: Lymphoproliferative disorder and imbalanced T-helper response in C/EBP beta-deficient mice. EMBO J 1995, 14:1932-1941.

29. Giulian D, Baker TJ: Characterization of ameboid microglia isolated from developing mammalian brain. J Neurosci 1986, 6:2163-2178.

30. Saura J, Tusell JM, Serratosa J: High-yield isolation of murine microglia by mild trypsinization. Glia 2003, 44:183-189.

31. Gresa-Arribas N, Serratosa J, Saura J, Sola C: Inhibition of CCAAT/enhancer binding protein delta expression by chrysin in microglial cells results in anti-inflammatory and neuroprotective effects. J Neurochem 2010, 115:526-536.

32. Saura J, Petegnief V, Wu X, Liang Y, Paul SM: Microglial apolipoprotein E and astroglial apolipoprotein $\mathrm{J}$ expression in vitro: opposite effects of lipopolysaccharide. J Neurochem 2003, 85:1455-1467.

33. Livak KJ, Schmittgen TD: Analysis of relative gene expression data using real-time quantitative PCR and the 2(-Delta Delta C(T)) Method. Methods 2001, 25:402-408.

34. Buira SP, Dentesano G, Albasanz JL, Moreno J, Martin M, Ferrer I, Barrachina M: DNA methylation and Yin Yang-1 repress adenosine A2A receptor levels in human brain. J Neurochem 2010, 115:283-295.

35. Liu YW, Tseng HP, Chen LC, Chen BK, Chang WC: Functional cooperation of simian virus 40 promoter factor 1 and CCAAT/enhancer-binding protein beta and delta in lipopolysaccharide-induced gene activation of IL-10 in mouse macrophages. J Immunol 2003, 171:821-828.

36. Glass CK, Saijo K, Winner B, Marchetto MC, Gage FH: Mechanisms underlying inflammation in neurodegeneration. Cell 2010, 140:918-934.

37. Sola C, Casal C, Tusell JM, Serratosa J: Astrocytes enhance lipopolysaccharide-induced nitric oxide production by microglial cells. Eur J Neurosci 2002, 16:1275-1283.

38. Saura J, Angulo E, Ejarque A, Casado V, Tusell JM, Moratalla R, Chen JF, Schwarzschild MA, Lluis C, Franco R, Serratosa J: Adenosine A2A receptor stimulation potentiates nitric oxide release by activated microglia. $J$ Neurochem 2005, 95:919-929.

39. Saura J: Microglial cells in astroglial cultures: a cautionary note. $J$ Neuroinflammation 2007, 4:26.

40. Sterneck E, Tessarollo L, Johnson PF: An essential role for C/EBPbeta in female reproduction. Genes Dev 1997, 11:2153-2162. 
41. Schroder K, Sweet MJ, Hume DA: Signal integration between IFNgamma and TLR signalling pathways in macrophages. Immunobiology 2006, 211:511-524.

42. Meir O, Dvash E, Werman A, Rubinstein M: C/EBP-beta regulates endoplasmic reticulum stress-triggered cell death in mouse and human models. PLoS One 2010, 5:e9516.

43. Nerlov C: C/EBPs: recipients of extracellular signals through proteome modulation. Curr Opin Cell Biol 2008, 20:180-185.

44. Xia C, Cheshire JK, Patel H, Woo P: Cross-talk between transcription factors NF-kappa B and C/EBP in the transcriptional regulation of genes. Int J Biochem Cell Biol 1997, 29:1525-1539.

45. Ejarque-Ortiz A, Gresa-Arribas N, Straccia M, Mancera P, Sola C, Tusell JM, Serratosa J, Saura J: CCAAT/enhancer binding protein delta in microglial activation. J Neurosci Res 2010, 88:1113-1123.

46. Ramberg V, Tracy LM, Samuelsson M, Nilsson LN, Iverfeldt K: The CCAAT/ enhancer binding protein (C/EBP) delta is differently regulated by fibrillar and oligomeric forms of the Alzheimer amyloid-beta peptide. $J$ Neuroinflammation 2011, 8:34.

47. Gorgoni B, Maritano D, Marthyn P, Righi M, Poli V: C/EBP beta gene inactivation causes both impaired and enhanced gene expression and inverse regulation of IL-12 p40 and p35 mRNAs in macrophages. J Immunol 2002, 168:4055-4062.

48. Merrill JE, Ignarro LJ, Sherman MP, Melinek J, Lane TE: Microglial cell cytotoxicity of oligodendrocytes is mediated through nitric oxide. $J$ Immunol 1993, 151:2132-2141.

49. Chen J, Ivashkiv LB: IFN-gamma abrogates endotoxin tolerance by facilitating Toll-like receptor-induced chromatin remodeling. Proc Natl Acad Sci USA 2010, 107:19438-19443.

50. Schwartz C, Beck K, Mink S, Schmolke M, Budde B, Wenning D, Klempnauer KH: Recruitment of $\mathrm{p} 300$ by C/EBPbeta triggers phosphorylation of p300 and modulates coactivator activity. EMBO J 2003, 22:882-892.

51. Li H, Gade P, Nallar SC, Raha A, Roy SK, Karra S, Reddy JK, Reddy SP, Kalvakolanu DV: The Med1 subunit of transcriptional mediator plays a central role in regulating CCAAT/enhancer-binding protein-beta-driven transcription in response to interferon-gamma. J Biol Chem 2008, 283:13077-13086.

52. Hanisch UK, Kettenmann H: Microglia: active sensor and versatile effector cells in the normal and pathologic brain. Nat Neurosci 2007, 10:1387-1394.

53. Katsuki H, Okawara M, Shibata H, Kume T, Akaike A: Nitric oxide-producing microglia mediate thrombin-induced degeneration of dopaminergic neurons in rat midbrain slice culture. J Neurochem 2006, 97:1232-1242.

54. Xie Z, Wei M, Morgan TE, Fabrizio P, Han D, Finch CE, Longo VD: Peroxynitrite mediates neurotoxicity of amyloid beta-peptide1-42- and lipopolysaccharide-activated microglia. J Neurosci 2002, 22:3484-3492.

55. Liberatore GT, Jackson-Lewis V, Vukosavic S, Mandir AS, Vila M, McAuliffe WG, Dawson VL, Dawson TM, Przedborski S: Inducible nitric oxide synthase stimulates dopaminergic neurodegeneration in the MPTP model of Parkinson disease. Nat Med 1999, 5:1403-1409.

56. Mount MP, Lira A, Grimes D, Smith PD, Faucher S, Slack R, Anisman $H$ Hayley S, Park DS: Involvement of interferon-gamma in microglialmediated loss of dopaminergic neurons. J Neurosci 2007, 27:3328-3337.

57. Chen H, Jacobs E, Schwarzschild MA, McCullough ML, Calle EE, Thun MJ, Ascherio A: Nonsteroidal antiinflammatory drug use and the risk for Parkinson's disease. Ann Neurol 2005, 58:963-967.

58. Gao X, Chen H, Schwarzschild MA, Ascherio A: Use of ibuprofen and risk of Parkinson disease. Neurology 2011, 76:863-869.

59. in't Veld BA, Ruitenberg A, Hofman A, Stricker BH, Breteler MM: Antihypertensive drugs and incidence of dementia: the Rotterdam Study. Neurobiol Aging 2001, 22:407-412.

60. Sterneck E, Johnson PF: CCAAT/enhancer binding protein beta is a neuronal transcriptional regulator activated by nerve growth factor receptor signaling. J Neurochem 1998, 70:2424-2433.

doi:10.1186/1742-2094-8-156

Cite this article as: Straccia et al.: Pro-inflammatory gene expression and neurotoxic effects of activated microglia are attenuated by absence of CCAAT/enhancer binding protein $\beta$. Journal of Neuroinflammation 2011 8:156.

\section{Submit your next manuscript to BioMed Central and take full advantage of:}

- Convenient online submission

- Thorough peer review

- No space constraints or color figure charges

- Immediate publication on acceptance

- Inclusion in PubMed, CAS, Scopus and Google Scholar

- Research which is freely available for redistribution

Submit your manuscript at www.biomedcentral.com/submit
Biomed Central 